\title{
Glycerol based solvents: synthesis, properties and applications
}

\author{
José I. García, ${ }^{* a}$ Héctor García-Marín ${ }^{a}$ and Elísabet Pires ${ }^{a}$
}

The most recent advances in the use of glycerol and glycerol derivatives as solvents are reviewed. There $s$ is an increasing number of examples on the use of glycerol itself as reaction medium, solvent-reagent or dispersive medium for a large variety of applications. In the case of glycerol derivatives, new synthetic methods, physico-chemical properties and application examples as solvents are revised. Recent works in the field of solvent classification, as well as solvent substitution issues, in connection with glycerol derivatives are also discussed in this review.

\section{Introduction}

Glycerol (also known as glycerin) is a polyol (1,2,3-propanetriol), 15 naturally present in the structure of triglycerides, which are fatty acid esters of this alcohol. There are currently a high number of applications found for this substance (more than 2000) in different fields such as the cosmetic, pharmaceutical or food industry, where it is mainly employed as humectant, thickener, 20 lubricant, sweetener or anti-freezer, among others uses. ${ }^{1}$ Because of the high industrial demand of this substance, chemical transformations from propene - a petroleum-derived productwere developed in the past to synthesize glycerol, mainly through two oxirane intermediates: glycidol and epichlorohydrin (Scheme

251 ). Its production from soap manufacture or fatty acid production was quantitatively less important.

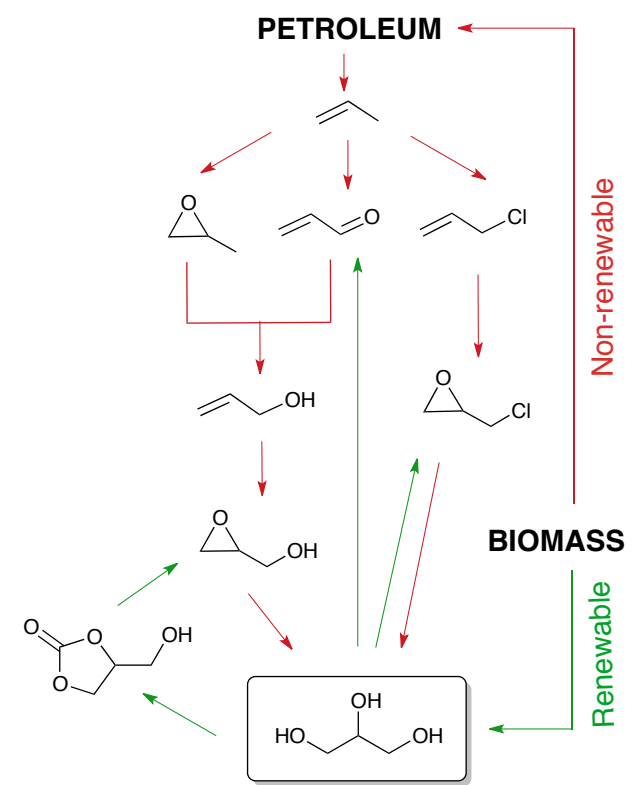

Scheme 1 From petroleum derived products to glycerol and back. Petrochemical vs. oleochemical sources of commodities.
However, the exponential growth in the production of biodiesel in the last years has changed this situation dramatically (Figure 1). In the production of biodiesel glycerol appears as a concomitant, representing ca. $10 \%$ wt. of the total output. In the 40 last years, the world glycerol production has surpassed 2 million metric tons, glycerol coming from biodiesel industry representing more than two-thirds of the total outcome.

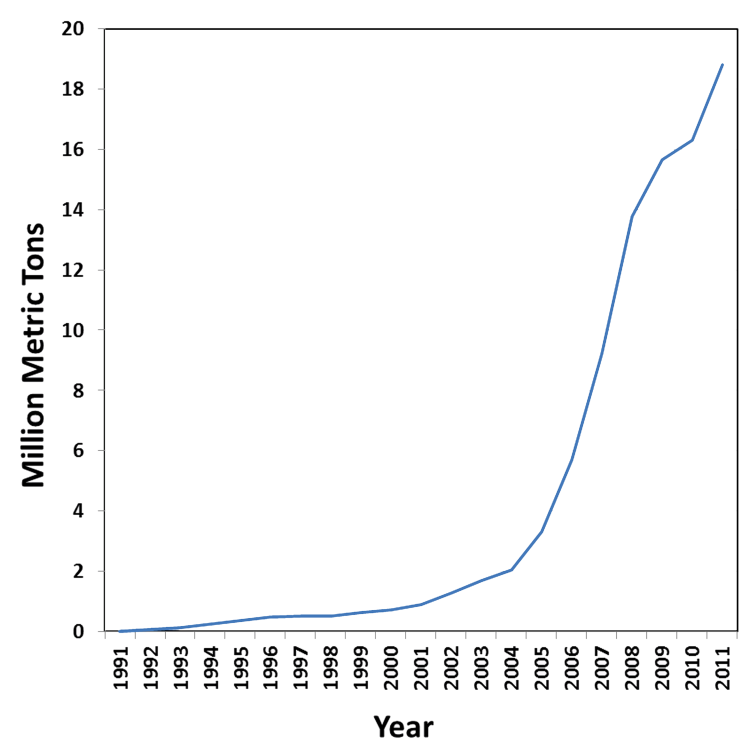

Fig. 1. World biodiesel production, 1991-2011 (source F. O. Licht; 45 Worldwatch).

The surpluses in the production of glycerol resulted in a decreasing trend in the price of crude glycerol and, to a lesser extent, also in the pharma quality glycerol (at least $99.5 \%$ pure), given that the traditional industrial uses of this substance were not ${ }_{50}$ able to absorb these surpluses. As a consequence, in the last years an increasing interest has been raised in the research of new uses of glycerol, able to deal with the high volume availability of this product, as highlighted by the increasing number of publications on this topic (Figure 2). 


\section{Instituto de Sintesis Química y Catálisis Homogénea}

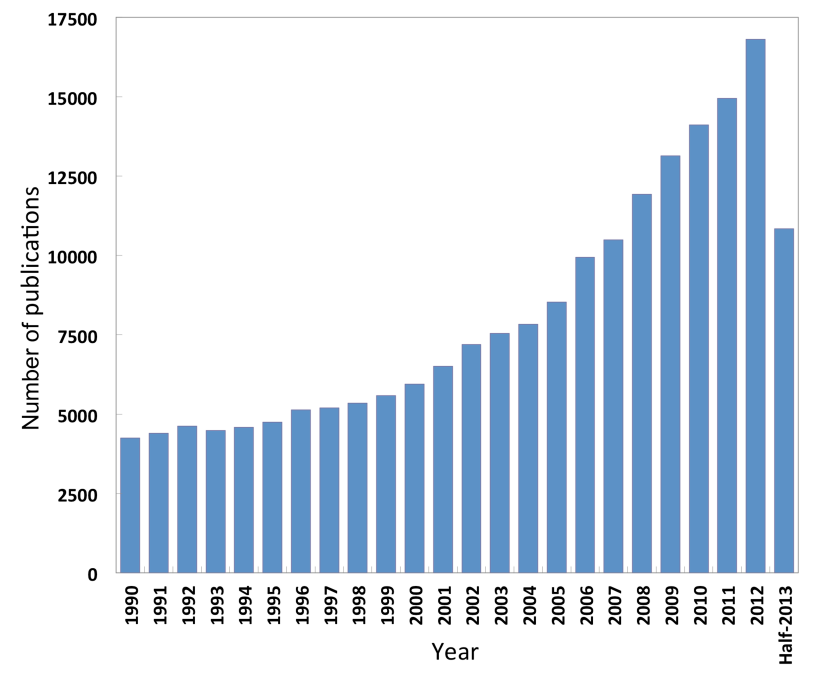

Fig. 2 Number of publications containing "glycerol" as topic, 1990-Present (source SciFinder ${ }^{\circledR}$ ).

From the mid-2000 several reviews have been published ${ }_{5}$ dealing with this subject. ${ }^{2-4}$ One of the most popular approaches consists in transforming glycerol in other small platform molecules that are added-value commodity chemicals, like glycidol, epichlorohydrin, acrolein, propylene glycol, etc..$^{3,5-8,4,9,10}$ In a sense, this represent the green "way back" in the pathways ${ }_{10}$ displayed in Scheme 1, in which the non-renewable petroleum source has been substituted by a renewable product coming from biomass. At the end of this way we would find the conversion of glycerol into olefins, such as propene or ethylene, a perspective that has been reviewed very recently. ${ }^{11}$

15 One of the possible new uses of glycerol and its derivatives, able to consume large amounts of this product, is that of solvent. Solvents are needed in huge amounts for very different industrial applications, including as reaction media, dispersant media and cleaning agents. Just as the majority of the organic substances, 20 organic solvents are currently petroleum-derived, and many of them are hazardous volatile compounds, toxic, and harmful. The search of less harmful, biodegradable, non-toxic green solvents able to replace conventional organic solvents is an active area of research. In this context, the use of glycerol itself, ${ }^{12,13}$ as well as

${ }_{25}$ some of its derivatives, as solvents has already been object of some recent reviews. ${ }^{14,15}$ Therefore, in this review we will mainly focus on the most recent papers published on this topic, paying particular attention to the synthesis and applications of these solvents. We will also devote a section to solvent properties and 30 solvent substitution issues.

We can classify glycerol-derived solvents in two very different groups. In the first one, we find "classical" glycerol derivatives that have been traditionally used as solvents, such as esters (like acetins), carbonates (glycerol carbonate), acetals (glycerol

35 formal) and ketals (solketal). In the second group we find organic solvents that are usually prepared from other sources, but for which synthesis starting from glycerol have been described, and may become competitive as the price of glycerol decreases. It is the case of propylene glycol, 1,3-propanediol, ethyl lactate or 40 butanol. Most of the review will focus on the first group of solvents, but some attention will be also paid to the second emergent group.

\section{Glycerol}

Glycerol, being a polyol, is able to dissolve many organic and ${ }_{45}$ inorganic compounds, including transition-metal complexes. Its immiscibility with some common organic solvents, such as hydrocarbons, ethers and esters, allows an easy separation of reaction products, and in the best cases, the possibility of reusing the glycerol phase in further reactions. This is particularly useful ${ }_{50}$ in the case of reactions catalyzed by transition metal complexes.

The use of glycerol as solvent has also several well-known drawbacks, like its high viscosity $\left(1200 \mathrm{cP}\right.$ at $\left.20^{\circ} \mathrm{C}\right)$ and the low solubility of highly hydrophobic compounds and gases, which limits its possible applications. The viscosity drawback is usually ${ }_{55}$ overcome by heating above $60{ }^{\circ} \mathrm{C}$ or by using co-solvents, but also by using high-intensity ultrasound or microwaves activation in a standalone or combined manner. Glycerol is a well-suited solvent for these kinds of activation, since it allows excellent acoustic cavitation even at high temperatures, and its dielectric ${ }_{60}$ properties (dipole moment $=2.67 \mathrm{D}$; dielectric permittivity $=$ 41.01 at r.t.) result in a quick and efficient heating, favoring both the mass transfer (by decreasing the viscosity of the medium) and the reaction kinetics. Moreover, its high boiling point allows carrying out reactions at high temperature without losing solvent ${ }_{65}$ by evaporation.

As already mentioned, the use of glycerol itself as reaction medium for chemical transformations has been the subject of several recent reviews. ${ }^{12,13}$ Therefore, we will only focus on the most recent applications reported in the literature, the majority of 70 them appeared in the present decade.

Glycerol has been found to be an interesting reaction medium in organic synthesis, both with and without the help of a catalyst, which is illustrated for the increasing number of papers appeared in the last years describing such applications. Glycerol as been 75 used, for these and other miscellaneous applications, as a single solvent, as co-solvent, being part of a deep eutectic mixture, or playing the double role of solvent and reagent.

\section{Non-catalyzed organic synthesis}

Glycerol has been used as a solvent for aza-Michael addition of 80 aromatic amines to electron-deficient $\alpha, \beta$-unsaturated ketones. Aromatic amines react smoothly with chalcone, 2-cyclohexen-1one, 2-cyclopenten-1-one, and ethyl vinyl ketone to achieve good to excellent yields of the corresponding $\beta$-aminoketone (Scheme 2). ${ }^{16}$ Results obtained are far better than those observed with 85 ionic liquids. The recyclability of glycerol has been studied in the case of the reaction of aniline and chalcone. Upon reaction completion, the reaction crude is extracted with ethyl acetate and purified by flash chromatography. The residual glycerol phase can be directly reused up to five times in subsequent reactions.

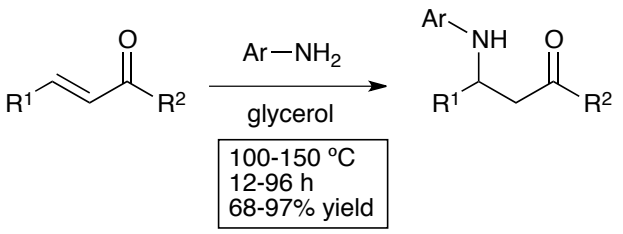


Scheme 2 Non-catalyzed aza-Michael addition of aromatic amines to $\alpha, \beta$-unsaturated ketones in glycerol.

3-Substituted 4-hydroxycoumarin and 4-hydroxypyrone derivatives have been obtained with good to excellent yields 5 through $C$-alkylation of 4-hydroxycoumarin and 4hydroxypyrone via in situ generated o-quinone methides with electron-rich tertiary aromatic amines in glycerol at room temperature (Scheme 3). ${ }^{17}$ The results obtained with glycerol outperform those obtained with water or common organic 10 solvents (Table 1).<smiles>[H][R]1ccccc1/C=C1\C(=O)Oc2ccccc2C1=O</smiles>

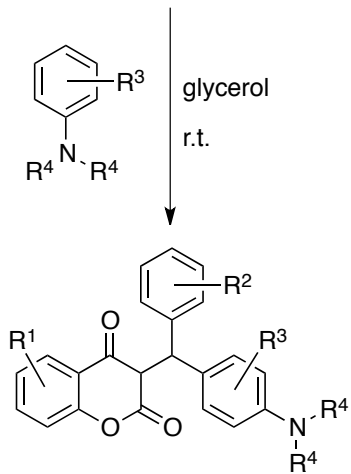

Scheme 3 Non-catalyzed $C$-alkylation of 4-hydroxycoumarins with aromatic aldehydes and tertiary aromatic amines in glycerol

Table 1 Comparison of the results of the alkylation of 4-hydroxy15 coumarin with benzaldehyde and 3-methyl- $N, N$-dimethylaniline in different solvents at room temperature

\begin{tabular}{ccc}
\hline Solvent & Time $(\mathrm{h})$ & Isolated yield (\%) \\
\hline $\mathrm{CH}_{2} \mathrm{Cl}_{2}$ & 8 & 0 \\
$\mathrm{CHCl}_{3}$ & 8 & 0 \\
Toluene & 8 & 0 \\
$\mathrm{THF}$ & 8 & 0 \\
Dioxane & 8 & Trace \\
$\mathrm{CH}_{3} \mathrm{CN}$ & 8 & Trace \\
$\mathrm{DMF}$ & 7 & $<6$ \\
$\mathrm{DMSO}$ & 7 & $<6$ \\
$\mathrm{MeOH}$ & 7 & 15 \\
EtOH & 7 & 20 \\
$\mathrm{H}_{2} \mathrm{O}$ & 5 & 40 \\
$\mathrm{Glycerol}$ & 3 & 95 \\
\hline
\end{tabular}

A similar example can be found in the electrophilic activation of aldehydes for the catalyst-free synthesis of 20 di(indolyl)methanes, xanthene-1,8-(2H)-diones and 1-oxohexahydroxanthenes. ${ }^{18}$ Glycerol has been described as an effective promoting medium for these kinds of reactions that are conventionally carried out using acid catalysts (Scheme 4).
2

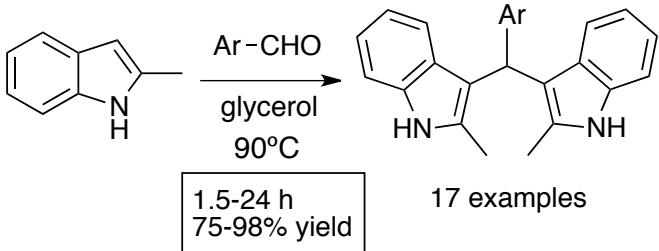

Scheme 4 Non-catalyzed synthesis of di(indolyl)methanes in glycerol

Also related to the previous examples, multicomponent reactions of 1,3-disubstituted 5-pyrazolones and formaldehyde have been carried out in environmentally benign solvent systems, glycerol among them. ${ }^{19}$ 2-Phenylindoles, styrenes and 30 vinylferrocene react in glycerol with 1,3-disubstituted 5pyrazolones and formaldehyde in the absence of any catalyst to afford a variety of complex structures in moderate to excellent yields. Two-step sequential reactions of phenylhydrazines, $\beta$ ketone esters, formaldehyde and styrenes or indoles have been 35 developed, allowing the synthesis of 1,3-disubstituted 5pyrazolones in glycerol (Scheme 5).

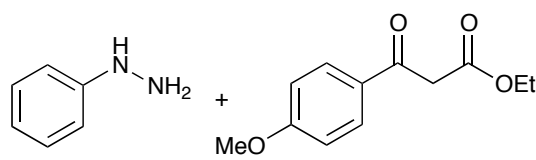

glycerol $110^{\circ} \mathrm{C}, 5 \mathrm{~h}$

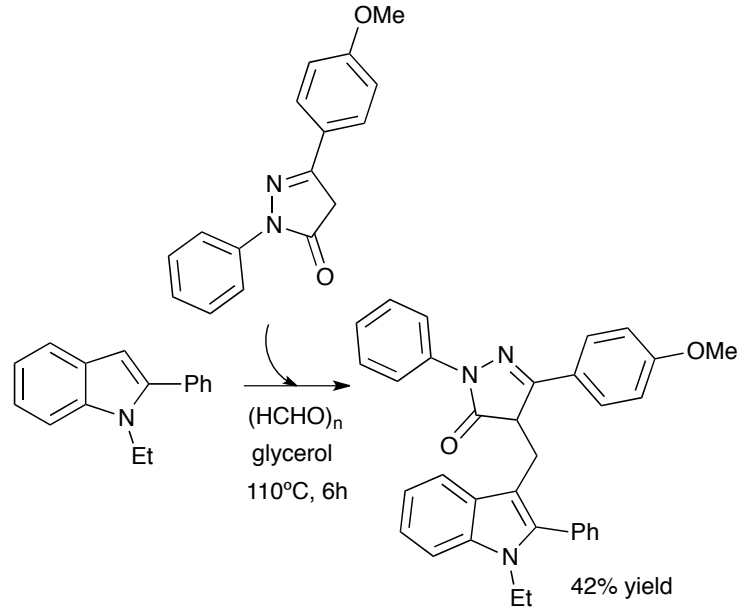

Scheme 5 Non-catalyzed two-step sequential synthesis of 1,3disubstituted 5-pyrazolones in glycerol

40 Glycerol has been employed as an efficient and a recyclable solvent in the thioacetalization of aldehydes and ketones (Scheme $6){ }^{20}$ The catalyst-free reactions proceed easily using glycerol at $90{ }^{\circ} \mathrm{C}$. The corresponding acyclic or cyclic thioacetals are obtained in good to excellent yields. As in precedent cases, 45 glycerol can be easily recovered and reused up to four more times in further reactions, with yields ranging from $90 \%$ to $96 \%$.

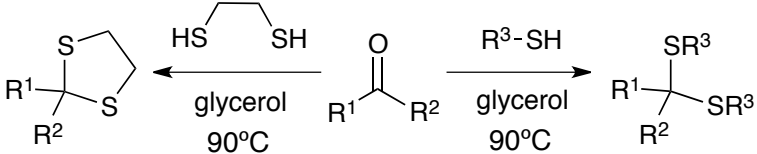


Scheme 6 Non-catalyzed synthesis of thioacetals in glycerol

Oxidation of different thiols under microwave irradiation has also been carried out efficiently using glycerol as solvent. ${ }^{21}$ The corresponding disulfides are obtained in good to excellent yields $5(74-93 \%)$ in short reaction times (15 min.). Glycerol can be easily recovered by extracting the reaction crude with a mixture of hexane/ethyl acetate 95:5, and then reused in subsequent reactions after drying under vacuum (Table 2).

Table 2 Recycling of glycerol in the oxidation of thiophenol under 10 microwave (MW) activation

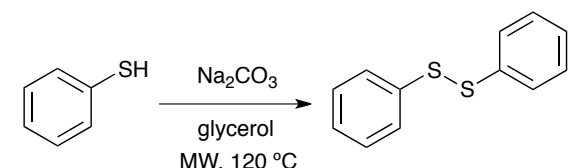

\begin{tabular}{ccc}
\hline Run & Time $(\min )$ & Isolated yield (\%) \\
\hline 1 & 15 & 92 \\
2 & 15 & 92 \\
3 & 15 & 90 \\
4 & 20 & 89 \\
5 & 30 & 88 \\
\hline
\end{tabular}

Glycerol has been used as a green solvent in the nucleophilic substitution of benzyl halides and ammonium acetate. ${ }^{22}$ Glycerol 15 facilitated the solubility of the organic reagent and the ammonium salt and also allowed the easy separation of the reaction product.

One of the widest application of glycerol as solvent in noncatalyzed organic synthesis is the preparation of heterocyclic 20 compounds by condensation procedures. For instance, a highly efficient method for the one-pot three-component synthesis of $4 H$-pyran derivatives using glycerol as reaction solvent has been recently described (Scheme 7). ${ }^{23}$ Glycerol leads to much better results than conventional organic solvents like toluene, DMF or ${ }_{25}$ ethanol, and outperforms the results obtained in ethylene glycol, PEG400 and water, leading to higher yields at lower temperature and reaction time.

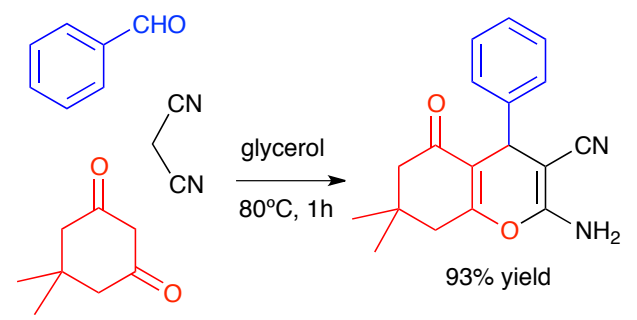

Scheme 7 Non-catalyzed one-pot three-component synthesis of $4 H$-pyran 30 derivatives in glycerol

Glycerol has been employed as solvent for the one-pot synthesis of 2-arylbenzothiazoles at room temperature with excellent yields. ${ }^{24}$ Furthermore, the products can be easily recovered in pure form from the reaction mixture (Scheme 8).

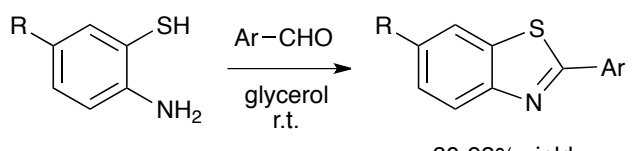

$80-93 \%$ yield
Scheme 8 Non-catalyzed one-pot synthesis of 2-arylbenzothiazoles in glycerol

A simple and efficient method has been described for the use of glycerol as solvent in the catalyst-free synthesis of 40 benzodiazepines and benzimidazoles. ${ }^{25}$ The corresponding $1 H$ 1,5-benzodiazepines and 1,2-disubstituted benzimidazoles are obtained in good yields by the condensation of 1,2diaminobenzene with different ketones and aldehydes, respectively (Scheme 9).

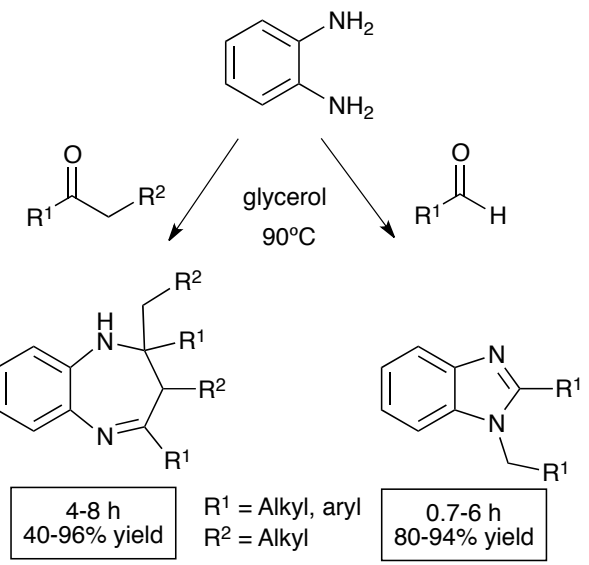

Scheme 9 Non-catalyzed synthesis of $1 H$-benzodiazepines and benzimidazoles in glycerol

The recyclability of glycerol in this reaction was also investigated. After completion of condensation, the reaction 50 mixture was extracted with hexane/ethyl acetate (95:5) and the glycerol phase was dried and reused up to four more times, with only a slight decrease in product yield (from $91 \%$ in the first use to $85 \%$ in the fifth). ${ }^{25}$

Similarly, benzoxazole, benzimidazole and quinoxaline rings ${ }_{55}$ have also been obtained by condensation of carbonyl compounds with 2-aminophenol and 1,2-diaminobenzenes in glycerol:water mixtures, with yields that were comparable to or better than those obtained in conventional media (Scheme 10). It is noteworthy that in this case, the presence of water (or methanol) is necessary ${ }_{60}$ to obtain such good yields. ${ }^{26}$
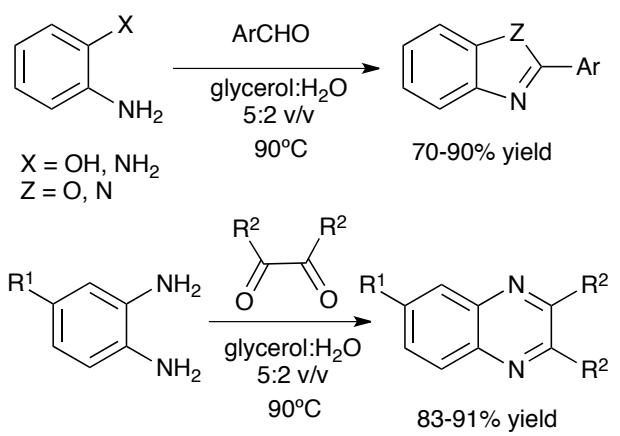

Scheme 10 Non-catalyzed synthesis of benzoxazoles, benzimidazoles and quinoxalines in a glycerol:water mixture

Related to the previous examples, the synthesis of substituted ${ }_{65}$ 2-thio-benzothia(oxa)zoles, 2-thiobenzimidazoles, and 1,3oxazolopyridine-2-thiols has been accomplished by cyclization of 
2-aminophenols, 2-aminothiophenols, 1,2-diaminobenzenes, or 2amino-3-hydroxypyridines with potassium $O$-ethyl dithiocarbonate in glycerol under microwave irradiation (Scheme 11). ${ }^{27}$ The best yields are obtained when the reaction mixture is 5 irradiated for $5 \mathrm{~min}$ at $30 \mathrm{~W}$ or for 2 min at $45 \mathrm{~W}$.

$$
\begin{aligned}
& \mathrm{X}=\mathrm{OH}, \mathrm{SH}, \mathrm{NH}_{2} \\
& \mathrm{Y}=\mathrm{CH}, \mathrm{N} \\
& \mathrm{R}=\mathrm{S}, \mathrm{N}, \mathrm{O}, \mathrm{Me}, \mathrm{NO}_{2}, \mathrm{COPh}
\end{aligned}
$$

Scheme 11 Non-catalyzed synthesis of 2-thio-benzothia(oxa)zoles, 2thiobenzimidazoles, and 1,3-oxazolopyridine-2-thiols in glycerol

Finally, octahydroacridines have also been prepared in good to 10 excellent yields by using glycerol as solvent in the one-pot imine condensation/hetero-Diels-Alder reaction of $(R)$-citronellal with substituted arylamines (Scheme 12). ${ }^{28}$ The catalyst-free reactions readily proceed using glycerol at $90{ }^{\circ} \mathrm{C}$ and the corresponding products are easily obtained by decantation. As in other previous 15 examples, glycerol can be directly reused in further reactions.

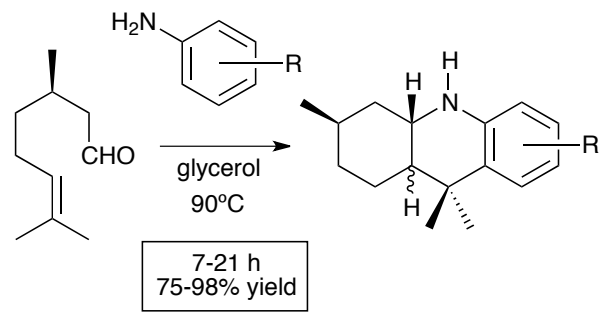

Scheme 12 Non-catalyzed synthesis of octahydroacridines in glycerol

\section{Catalyzed organic synthesis}

Examples of both homogeneous and heterogeneous catalysis of 20 organic reactions in glycerol have been described. In the case of homogeneous catalysis, glycerol may favor the solubilization of metal complex catalyst, as well as that of acid and basic catalysts. However, it should be borne in mind that in some cases, metal complexes are sensitive to the presence of hydroxyl groups, so ${ }_{25}$ glycerol is not a universally suitable solvent for this kind of catalysis. In this section we will revise those examples published on these topics in the very last years.

Glycerol has been used as solvent for the regioselective $\beta, \beta$ diarylation of alkyl acrylates in the presence of air-stable 30 palladium nanoparticles, through a Mizoroki-Heck reaction (Scheme 13). ${ }^{29}$

When the reaction is carried out at $120{ }^{\circ} \mathrm{C}$, the diarylated product is obtained in good yield. However, by adjusting the reaction temperature, the mono/diarylation product distribution 35 can be controlled, allowing the possibility of synthesizing unsymmetrical diarylated alkenes in two consecutive steps (Scheme 13). Reaction products are cleanly and selectively extracted from the glycerol-palladium catalytic phase using supercritical carbon dioxide. Unfortunately, the recycling of the 40 catalytic phase was unsuccessful due to the accumulation of salts after each reaction cycle. ${ }^{29}$

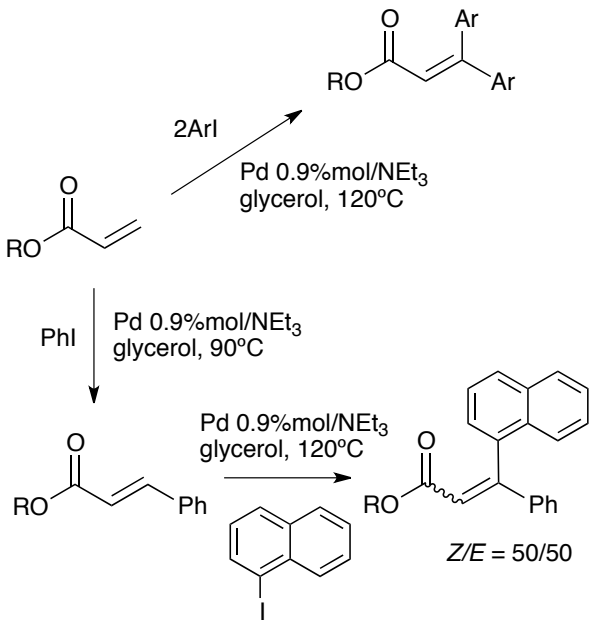

Scheme 13 Diarylation of acrylate derivatives in glycerol, catalyzed by palladium nanoparticles

Ring-closing metathesis reactions of $\mathrm{N}, \mathrm{N}$-diallyltosylamine and diethyl diallylmalonate in glycerol under microwave activation has been recently described, ${ }^{30}$ using the most common commercially available ruthenium catalysts (Scheme 14).

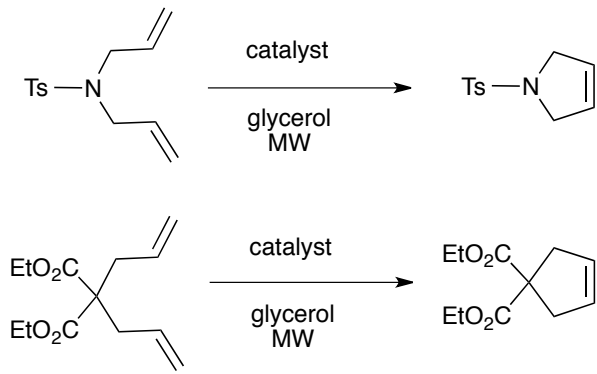

catalyst

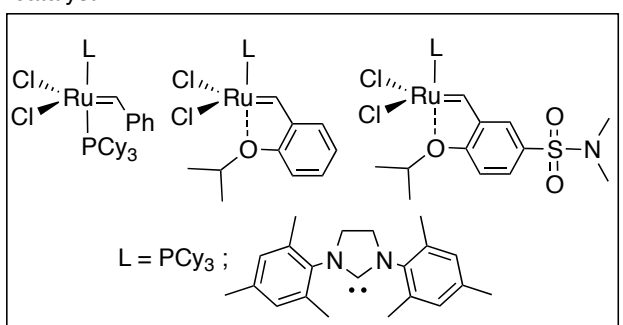

Scheme 14 Ring-closing metathesis in glycerol under microwave activation, catalyzed by ruthenium complexes

The reaction products could be easily isolated in high yield after extraction of the reaction crude with diethyl ether. Recycling 55 of the remaining phase was tested, the catalyst being recyclable twice without decrease of the final reaction yield. However, in the fourth run, the catalytic phase displayed a marked decrease in activity. NMR experiments demonstrated that part of the Ru catalyst is extracted to the ether phase during product isolation. ${ }_{60}$ However, this catalyst leaching does not seem to be fully responsible of the dramatic yield decrease observed, and the authors rather attribute this decrease to catalyst degradation. ${ }^{30}$

Glycerol has been employed as a novel solvent in the crosscoupling reaction of diaryl diselenides with a variety of vinyl 
bromides, catalyzed by $\mathrm{CuI} / \mathrm{Zn}$ (Scheme 15$).{ }^{31}$ The corresponding vinyl selenides were obtained in all cases in good to excellent yields after extraction of the reaction crude with hexanes. Furthermore the remaining mixture glycerol/ $\mathrm{CuI} / \mathrm{Zn}$ could be ${ }_{5}$ directly reused for further cross-coupling reactions up to five times.

The closely related copper-catalyzed cross-coupling reactions of diaryl diselenides with aryl boronic acids have also been carried out using glycerol as solvent (Scheme 15). ${ }^{32}$

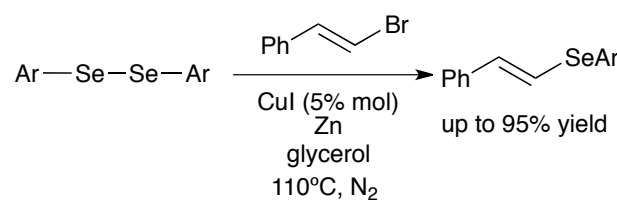

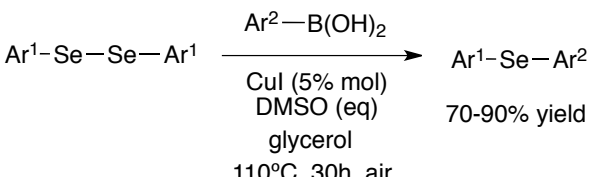

Scheme 15 Cross-coupling reactions of diaryl diselenides in glycerol, catalyzed by $\mathrm{CuI}$

In this case the catalyst employed was CuI, and DMSO was also used as additive. The corresponding diaryl selenides were 15 obtained in good to excellent yields. As in the precedent case, the glycerol/CuI mixture could be directly reused for further crosscoupling reactions (up to five cycles).

The copper-catalyzed coupling reaction of aryl halides with various aromatic and cyclic amines by using glycerol as solvent 20 has also been recently reported. ${ }^{33}$ The glycerol catalytic phase could readily be separated from the reaction mixture and reused for several runs without any loss in catalytic efficiency (Figure $3)$.

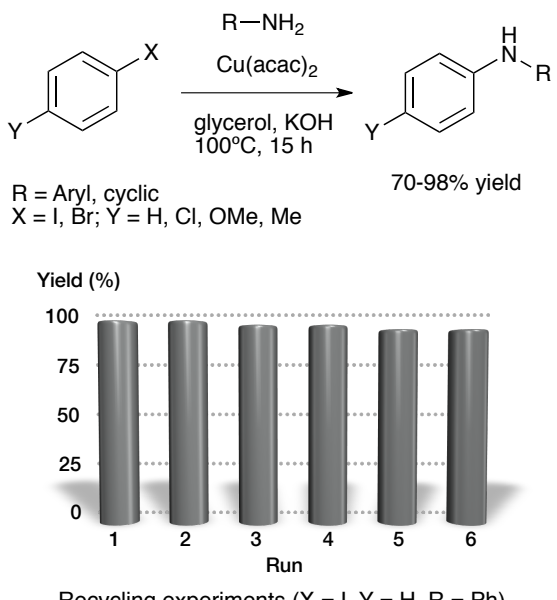

Recycling experiments $(\mathrm{X}=\mathrm{I}, \mathrm{Y}=\mathrm{H}, \mathrm{R}=\mathrm{Ph})$

25 Fig. 3 Coupling reaction of aryl halides with amines in glycerol, catalyzed by $\mathrm{Cu}(\mathrm{acac})_{2}$, and recycling experiments

[Fe(III)-(salen)]Cl catalyst has been used in multicomponent reactions for the synthesis of bis(indolyl)methanes, 3,4dihydropyrimidinones, and 1,4-dihydropyridines in glycerol

${ }_{30}$ (Scheme 16). ${ }^{34}$ Excellent product yields and short reaction times were achieved under microwave activation $(5 \times 1 \mathrm{~min} .300 \mathrm{~W}$ pulses).
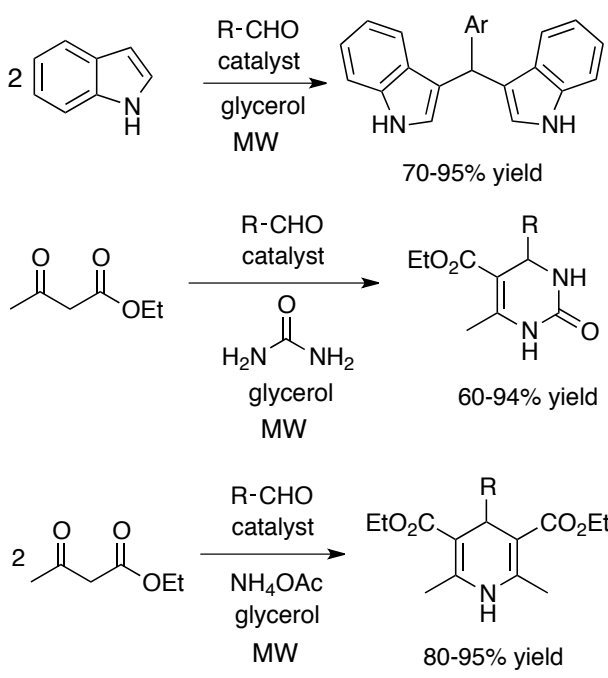

catalyst:

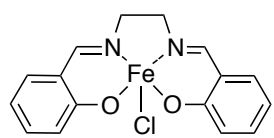

Scheme 16 Multicomponent reactions catalyzed by [Fe(III)-(salen)]Cl in glycerol

Brønsted acid catalysis of organic reactions has also been carried out in glycerol or aqueous solutions of glycerol. For instance, the one-pot synthesis of substituted pyrimidinone derivatives with aromatic aldehydes, cyclopentanone, and urea 40 (or thiourea) has been accomplished using boric acid and glycerol in aqueous medium at $45-50{ }^{\circ} \mathrm{C}$. $^{35}$

The use of glycerol and PS-PEG-OSO${ }_{3} \mathrm{H}$ has been described in multicomponent reactions for the synthesis of 3,4dihydropyrimidinones, amidoalkyl naphthols, and dibenzo${ }_{45}$ xanthenes, respectively. ${ }^{36}$ The products could be isolated in excellent yields by simple extraction, after which the catalytic phase could be recycled.

Ionic liquids (ILs) can be partially substituted by glycerol or glycerol carbonate as co-solvents in the acid-catalyzed ${ }_{50}$ dehydration of fructose and inulin to 5-hydroxymethylfurfural (HMF). ${ }^{37}$ HMF can be conveniently extracted from the IL/glycerol (65:35) mixture with methylisobutylketone, limiting the reactivity of glycerol with HMF and allowing the recovery of the desired product with a high purity $(95 \%)$.

55 Heterogeneous catalysts can also be used in combination with glycerol. This topic is addressed in a recent work, ${ }^{38}$ where several examples of organic transformations carried out in glycerol with the help of heterogeneous catalysis combined with ultrasound (US) and microwaves (MW) activation are given. One of these 60 transformations is the palladium-catalyzed Suzuki cross-coupling reaction (Scheme 17).

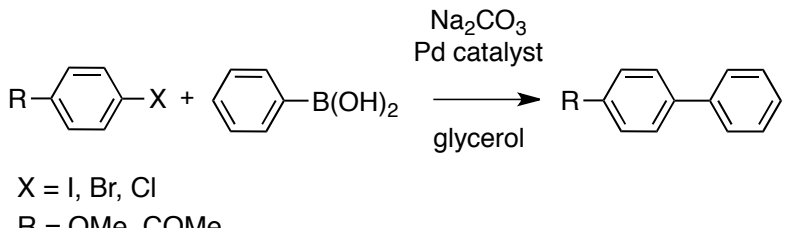


Scheme 17 Palladium-catalyzed Suzuki cross-coupling reaction in glycerol

Enhanced reaction rates were obtained in the reactions carried out in glycerol in the order US+MW $>$ US $>$ MW, with regard to the $s$ thermally activated reactions (Table 3 ).

Table 3 Cross-coupling yields in the reaction of 4-iodomethoxybenzene with phenylboronic acid in glycerol at $80{ }^{\circ} \mathrm{C}$, using different catalysts and activation methods

\begin{tabular}{ccccc}
\hline Method & Time (min) & \multicolumn{3}{c}{ Yield (\%) } \\
& & $\mathrm{Pd}(\mathrm{OAc})_{2}$ & $\mathrm{PdCl}_{2}$ & $\mathrm{Pd} / \mathrm{C}$ \\
\hline Oil bath & 60 & 85 & 75 & 44 \\
US+Oil bath & 60 & 99 & 98 & 86 \\
MW & 15 & 57 & 70 & 60 \\
MW & 60 & 74 & 92 & 67 \\
US+MW & 60 & 100 & 98 & 94 \\
\hline
\end{tabular}

10 Both US- and MW-irradiation greatly improve the reactions of otherwise poorly reactive halobenzenes, such as chloroacetophenone. Apart from those obtained with Pd/charcoal, excellent catalytic activities were also achieved using a different heterogeneous catalyst, namely a palladium-loaded cross-linked 15 chitosan. $^{38}$

Another example is the Barbier reaction (Scheme 18), in which metallic zinc powder is used to generate the organometallic reactive intermediate. The use of ultrasound activation together with glycerol allows obtaining quantitative yield of the reaction 20 product, which can be easily isolated through a simple extraction process using ethyl acetate. ${ }^{38}$

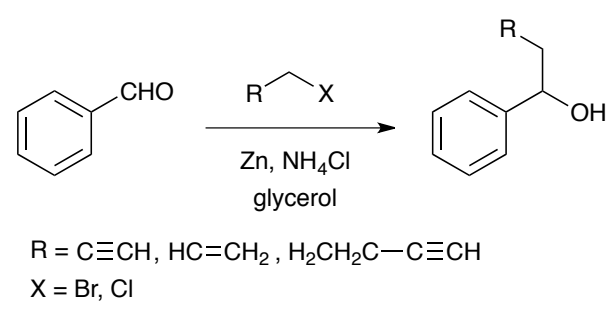

Scheme 18 Zinc-mediated Barbier reaction in glycerol

Glycerol has been successfully used in combination with a ${ }_{25}$ solid-supported basic catalyst $\left(\mathrm{KF} / \mathrm{Al}_{2} \mathrm{O}_{3}\right)$ as a recyclable system for the synthesis of several organylthioenynes in good to excellent yields and high selectivity, although in this case the use of PEG400 instead of glycerol proved to be superior. ${ }^{39}$ The corresponding alkenyl sulfides are preferentially obtained with $Z$ 30 configuration (Scheme 19). The catalytic system can be reused up to three times without previous treatment with comparable activity.

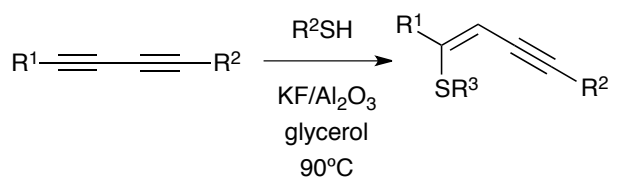

Scheme 19 Synthesis of organylthioenynes in glycerol

\section{Biotransformations}

Biotransformations can be considered as an especial type of catalytic reaction, which can be carried out either using enzymes or whole cells. The use of glycerol and glycerol derivatives as solvent in biotransformations has been recently gathered in a 40 review dealing on the use of green solvents in these kinds of processes. ${ }^{40}$ Thus, glycerol has been used as a green co-solvent in whole cell-catalyzed bioreductions of ketones, leading to excellent yields and stereoselectivity values. ${ }^{41,42}$ Glycerol is also widely employed in the biotransformations of terpenois or 45 aromatic ketones used in perfumes. ${ }^{42}$ Glycerol solubilizes the substrates and it is immiscible with traditionally used green solvents, such as ethyl acetate and recently $\mathrm{scCO}_{2}$, which allows the easy separation of the desired products from the reaction medium.

\section{${ }_{50}$ Dual Solvent-Reagent role}

As a polyol, glycerol can be used both as a green solvent and hydrogen donor in transfer hydrogenation reactions. For instance, its use has been reported for the ruthenium-catalyzed reduction of allylic alcohols. ${ }^{43}$ From a mechanistic point of view, this reaction 55 is indeed a tandem process involving the initial redoxisomerization of the allylic alcohol and subsequent transfer hydrogenation of the resulting carbonyl compound (Scheme 20). The best results, with yields up to $90 \%$, were obtained with the hydrophilic arene- $\mathrm{Ru}(\mathrm{II})$ complex $\left[\mathrm{RuCl}_{2}\left(\eta^{6}-\mathrm{C}_{6} \mathrm{H}_{6}\right)\right.$ (DAPTA)] ${ }_{60}(\mathrm{DAPTA}=$ 3,7-diacetyl-1,3,7-triaza-5-phosphabicyclo[3.3.1] nonane). It must be emphasized that these reduction processes are also operative using technical grade glycerol, an interesting goal that is scarcely achieved.

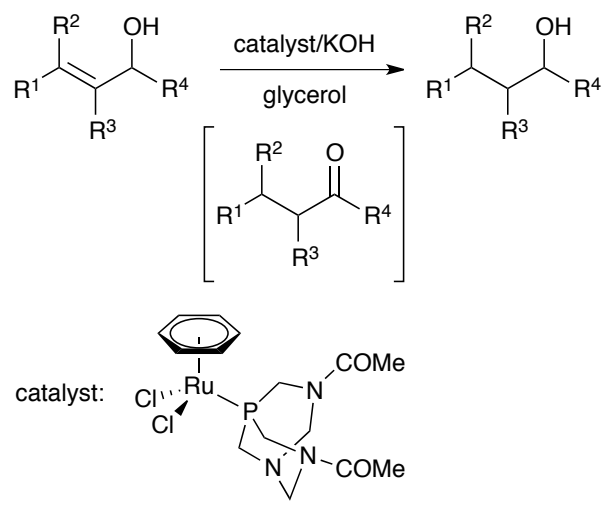

65 Scheme 20 ruthenium-catalyzed reductions of allylic alcohols in glycerol

Another example is the catalytic transfer hydrogenation of benzaldehyde to benzyl alcohol catalyzed by the $\operatorname{Ru}(p$ cumene) $\mathrm{Cl}_{2}$ complex (Scheme 21). ${ }^{38}$ The use of ultrasound dramatically increased the reaction yields. Presonication leads to 70 a good dispersion of the $\mathrm{KOH} / \mathrm{NaOH}$ solid mixture in glycerol, leading to a decrease in reaction times. ${ }^{38}$

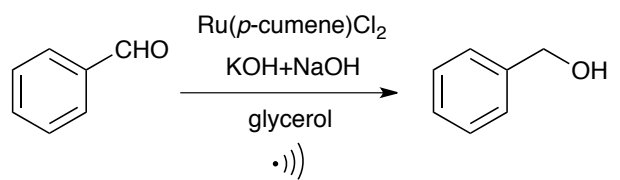

Scheme 21 Ru-catalyzed transfer hydrogenation of benzaldehyde in glycerol

75 Another recent example of transfer hydrogenation of carbonylic compounds in glycerol has been described, using 


\section{Instituto de Sintesis Química y Catálisis Homogéne}

iridium-NHC catalysts. ${ }^{44,45}$ The Ir(III) complexes proved to be most efficient in the reduction of ketones, while the $\operatorname{Ir}(\mathrm{I})$ complexes are more active in the reduction of aldehydes. As in the previous example, reaction sonication has huge impact $s$ in shortening reaction times.

Dioxomolybdenum(VI) complexes have been described as highly efficient catalysts for the chemoselective sulfoxide deoxygenation (Scheme 22). ${ }^{46}$ Glycerol is again successfully employed both as solvent and reducing agent. Either refined or

10 crude glycerol (even with purities as low as 5-8\%) can be used, thus expanding the potential application of this reaction.

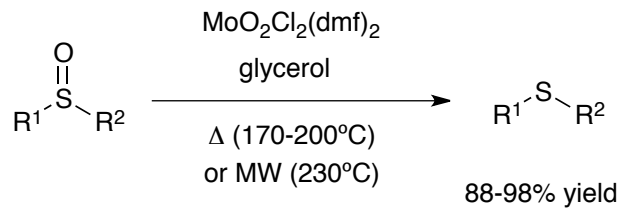

12 substrates

Scheme 22 Mo-catalyzed sulfoxide deoxygenation in glycerol

Diameter-controlled silver nanowires have been efficiently ${ }_{15}$ prepared using glycerol as both a reductant and a solvent under microwave irradiation. The thickness of obtained $\mathrm{Ag}$ nanowires can be controlled by adjusting the amounts of glycerol and $\mathrm{AgNO}_{3}{ }^{47}$ Similarly, the synthesis of gold nanoparticles has been achieved using glycerol-incorporated nanosized liposomes. ${ }^{48}$

\section{${ }_{20}$ Deep eutectic solvents containing glycerol}

Glycerol has been used as one of the components of deep eutectic mixtures, often labeled as deep eutectic solvents (DES), whose use as cheaper, environmentally friendlier alternatives to ionic liquids is receiving an increasing interest. Several recent reviews ${ }_{25}$ have appeared covering this topic, ${ }^{49-51}$ one of them exclusively devoted to glycerol eutectic mixtures. ${ }^{49}$ DES are characterized by lower melting points than those of their components. In most cases, DES consist of a quaternary ammonium salt and a hydrogen bond donor compound. Among the several alternatives 30 the use of choline chloride $(\mathrm{ChCl})$ offers the advantages of a low cost, good biodegradability and low toxicity. That is why most of the studies are focused on the use of this compound. When mixing glycerol with choline chloride in various proportions, the polarity of the resulting mixtures is slightly higher than that of 35 pure glycerol, with an increase in hydrogen bond donor ability, as well as in dipolarity-polarizability. The polarity of these mixtures is similar to that measured for ethylammonium nitrate. Furthermore, the viscosity of these mixtures is far lower than that of pure glycerol (400 cP for the 1:3 mixture of glycerol:choline 40 chloride vs. $1200 \mathrm{cP}$ of glycerol, at room temperature) and the density is lowered from $1.26 \mathrm{~g} \mathrm{~cm}^{-3}$ for pure glycerol to $1.18 \mathrm{~g}$ $\mathrm{cm}^{-3}$ for a mixture of $35 \%$ of $\mathrm{ChCl}$ in glycerol. These data have been recently broadened with new measurements of densities, refractive indices and viscosities of DES containing glycerol. ${ }^{52}$

45 DES containing glycerol appeared to be interesting media for $\mathrm{CO}_{2}$ and $\mathrm{SO}_{2}$ absorption. In the first case, ${ }^{53}$ the solubility in molality of $\mathrm{CO}_{2}$ in the DES was found to be comparable with the typical solubility of $\mathrm{CO}_{2}$ in ionic liquids. In the case of $\mathrm{SO}_{2}$ adsorption, ${ }^{54}$ the capacity of the DES with a $\mathrm{ChCl}$-glycerol molar ${ }_{50}$ ratio of $1: 1$ reached a value of $0.678 \mathrm{~g} \mathrm{SO}_{2}$ per g DES at $20^{\circ} \mathrm{C}$ and $1 \mathrm{~atm}$. Moreover, the absorbed $\mathrm{SO}_{2}$ could be easily released and the medium maintained its absorption/desorption capacity during five consecutive cycles.

Very recently, DES have been described as effective solvents ${ }_{55}$ for fuels desulfurization. ${ }^{55}$ In this study, extraction of benzothiophene, as representative sulfur-containing compound, from an n-octane solution using different DES was carried out. When using a mixture of tetrabutylammonium chloride and glycerol, extraction efficiency up to 55\% was achieved, although 60 this efficiency was better when PEG was used instead of glycerol as hydrogen bond donor compound in the mixture.

Another recent application of glycerol-based DES is the removal of residual $\mathrm{KOH}$ content from palm oil-based biodiesel. $^{56}$ The choline chloride:glycerol and methyltri${ }_{65}$ phenylphosphonium bromide:glycerol DES proved their superiority in removing the $\mathrm{KOH}$ from palm oil-based biodiesel, with an average removal efficiency of $98.6 \%$ and $97.6 \%$ respectively. Most of these DESs fulfilled international standards specification for $\mathrm{KOH}$ content at all DES:biodiesel molar ratios.

70 DES containing glycerol have also been used as reaction media. Some recent examples in biotransformations have been published, ${ }^{57}$ apart from the ones described by Jérôme and coworkers. ${ }^{50}$ Thus, the transesterification activities of cross-linked proteases (subtilisin and $\alpha$-chymotrypsin), immobilized on 75 chitosan, have been studied in these DES. In the 1:2 molar ratio mixture of choline chloride/glycerol containing 3\% (v/v) water, cross-linked subtilisin exhibited an excellent activity $(2.9 \mu \mathrm{mol}$ $\min ^{-1} \mathrm{~g}^{-1}$ ) and selectivity (98\%) in the transesterification reaction of $\mathrm{N}$-acetyl-1-phenylalanine ethyl ester with 1-propanol.

80 The use of biocatalysts in DES has been very recently reviewed by Durand et al. ${ }^{58}$ and Pérez-Sánchez et al. ${ }^{59}$

Glycerol based DES have also been described as catalyst/reaction media. Thus, glycerol, ChCl-glycerol ChCl-urea and ChCl-malonic acid have been tested in the synthesis of $\mathrm{N}$ ${ }_{85}$ arylphthalimide derivatives (Scheme 23). ${ }^{60}$ Using these media, yields were improved regarding the ones obtained in toluene, methanol or acetonitrile. Furthermore, the catalyst/solvent system could be reused up to four times without any loss in activity.

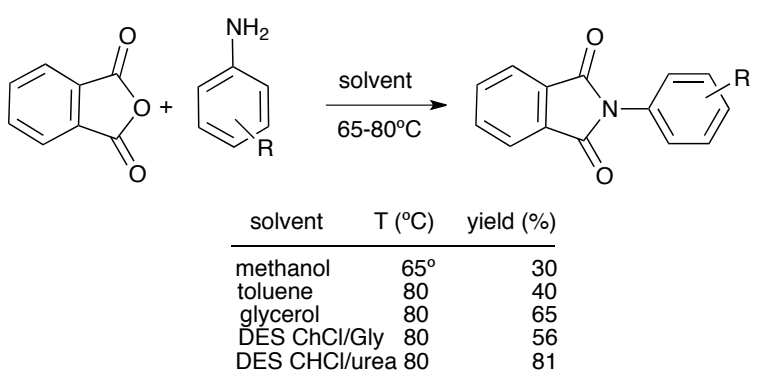

90 Scheme 23 Comparison of yields in $N$-arylphthalimide derivatives synthesis in conventional solvents and DES

Another interesting example of the use of DES as catalyst/solvent system is the one described by Handy and co-workers. ${ }^{61}$ in PaalKnorr reactions for the synthesis of pyrrols or furans. Again ${ }_{95} \mathrm{ChCl}$-urea and $\mathrm{ChCl}$-glycerol systems were evaluated (Scheme 24). 


\section{stituto de Sintesis Quimica y Catálisis Homogénea}

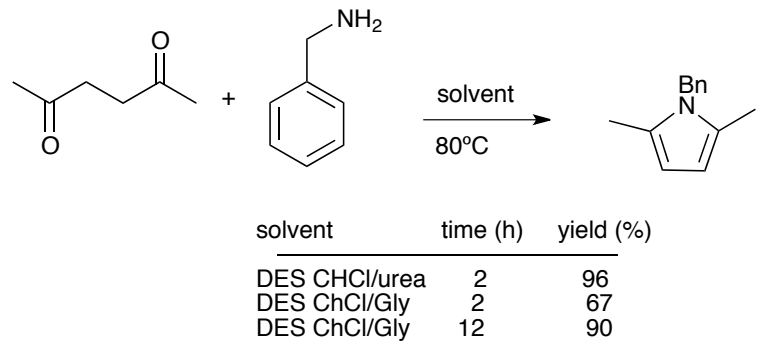

Scheme 24 Paal-Knorr reaction carried out in DES

In this case, the weaker hydrogen-bonding activation of glycerol compared to urea resulted in much weaker catalysis of the PaalKnorr reaction, and longer times were needed in order to reach 5 high yields. Again, DES could be recovered and reused up to four runs with a slight loss in activity.

\section{Miscellaneous applications}

In this section we describe some different applications of glycerol as solvent, not directly related with its uses as reaction medium or 10 reagent.

Glycerol is a promising solvent to be used as an alternative to DMSO and PEG3350 in biological assays when the probe molecules have a low aqueous solubility. ${ }^{62}$ Glycerol might provide acceptable solubilization of these kinds of molecules 15 while preserving the protein structure.

Although the high viscosity of glycerol is often considered as a drawback for its use as solvent, in some cases it can become an advantage. For instance, NMR of weakly polar analytes in ultraviscous solvents, like glycerol and glycerol carbonate, has 20 recently been proposed for mixture analysis as an alternative to DOSY experiments. ${ }^{63}$ In this recent work it has been shown how some dipeptides (Leu-Val, Leu-Tyr, Gly-Tyr and Ala-Tyr) slowly reorient in glycerol and glycerol carbonate under particular temperature conditions, so that solute resonances may 25 show spin diffusion in 1D- and 2D-NOESY experiments, thus opening the way to mixture analysis. Another example is the thermal isomerization of a colorless spirocyclic (SP) compound to a colored merocyanine (MC) form (Scheme 25), which is enhanced with an increase in the concentrations of 30 viscous solvents in solution. ${ }^{64}$ Equilibrium absorption analysis revealed that the enhanced $\mathrm{SP}$ to $\mathrm{MC}$ isomerization in viscous media is due to the strong solvent-solvent interaction, which suppresses the ordering of solvent molecules around the MC form. This results in a positive entropy change for isomerization 35 and, hence, promotes the entropy-driven isomerization.

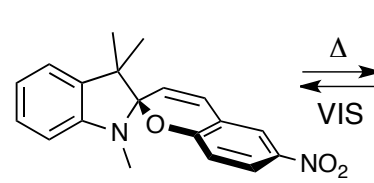

SP

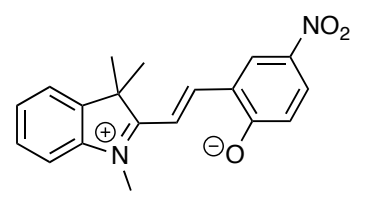

MC
Scheme 25 Entropy-driven thermal isomerization in glycerol

Silica microcapsules have been synthesized by hydrolysis and condensation of tetraethyl orthosilicate (TEOS) using aqueous 40 glycerol microemulsion as template. ${ }^{65}$

Glycerol has also been found to have applications in the treatment of lignocellulosic biomass. Thus, enzymatic hydrolysis of lignin (EHL), isolated from biomass residues, has been carried out using the mixed solvents of polyethyleneglycol (PEG) and ${ }_{45}$ glycerol at temperatures from $130{ }^{\circ} \mathrm{C}$ to $170{ }^{\circ} \mathrm{C}$ with sulfuric acid as catalyst. ${ }^{66}$ Direct liquefaction of lignocellulosic waste (sawdust) has been conducted in hot-compressed ethanol at temperatures from 150 to $250{ }^{\circ} \mathrm{C}$. It was found that polyols such as glycerol, glycol and polyethylene glycol (PEG) are able to so promote the liquefaction process. The conversion of sawdust in optimal conditions reaches $c a .98 \%{ }^{67}$

\section{Glycerol esters}

Esters derived from glycerol have also been used as solvents. In this section we will review the synthesis, properties and recent 55 applications of these derivatives.

\section{Synthesis}

The synthesis of glycerol esters can be carried out either by esterification reaction with carboxylic acids, usually catalyzed by acids, or by transesterification reactions catalyzed by bases 60 (Scheme 26).

The synthesis of mono- and diglycerides with long ester moieties has been reviewed in recent publications. ${ }^{68-70}$ In this review we will only summarize those works dealing with the synthesis of short glycerol esters, such as glyceryl acetates 65 (acetins), glyceryl propionates (propionins) and glyceryl butyrates (butyrins), which possess the most interesting properties as solvents.

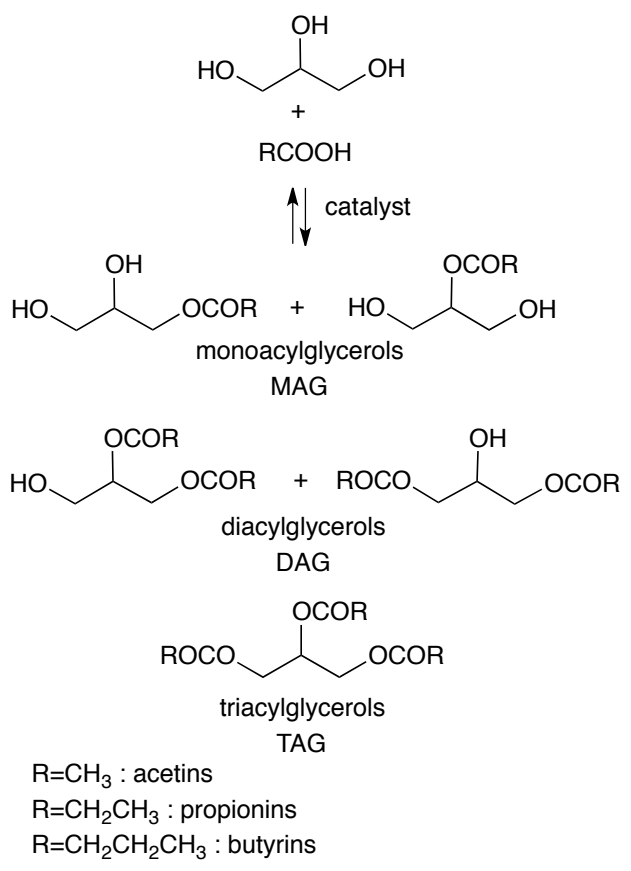

Scheme 26 Esterification of glycerol

70 A great attention has been paid to glycerol acetylation in the last few years and several works have been published dealing with the use of acid solid catalysts in this reaction. Glycerol conversion, and reaction selectivity towards mono, di or triacetin strongly depend on the nature of the surface of the catalyst 
(hydrophobicity-hydrophilicity) and the density and strength of the acid catalytic sites.

Exchanged resins such as Amberlyst 15, ${ }^{71,72}$ hybrid materials such as SBA $15,{ }^{73}$ supported heteropolyacids, ${ }^{74}$ and sulfonated 5 carbons ${ }^{75-77}$ have demonstrated their high activity in this reaction. Although it is difficult to do a comparative study of these results due to the different reaction conditions applied in each work. Recently, manuscripts dealing with the comparison of several acid solids, such as K10-montmorillonite, Amberlyst 15, Niobic 10 acid, HZSM-5, HUSY, SSBA, in the acetylation reaction of glycerol have been published. ${ }^{72,71,78}$ Results showed a poorer activity of zeolites, while sulfonated solids such as Amberlyst 15 or SSBA provided total glycerol conversions and higher triacetin selectivity (Figure 4).

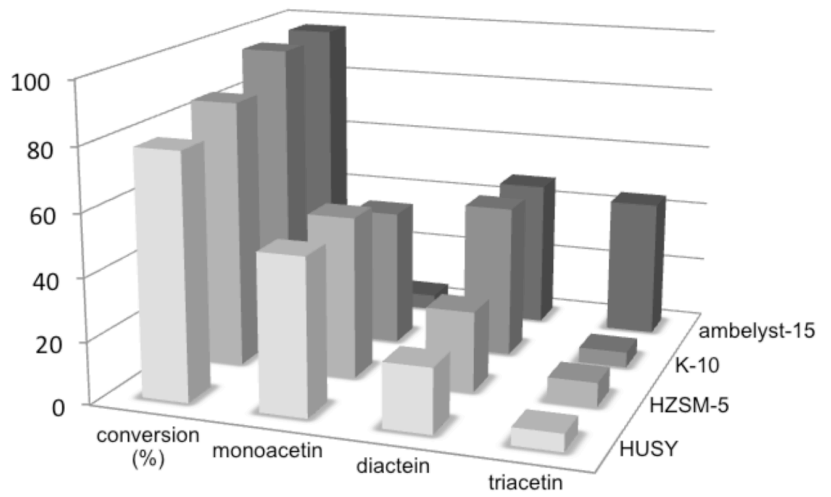

Fig. 4 Results of glycerol acetylation catalyzed by several solid acids

Due the interest of triacetin in many industrial applications, several methods have been described for its preparation in high yields. Some of them are based on the combination of ${ }_{20}$ esterification reaction of glycerol with acetic acid and subsequent acetylation of monoacetins and diacetins with acetic anhydride (Scheme 27) ${ }^{79-81}$ The same methodology has been also applied to the synthesis of tributyrin. ${ }^{82}$

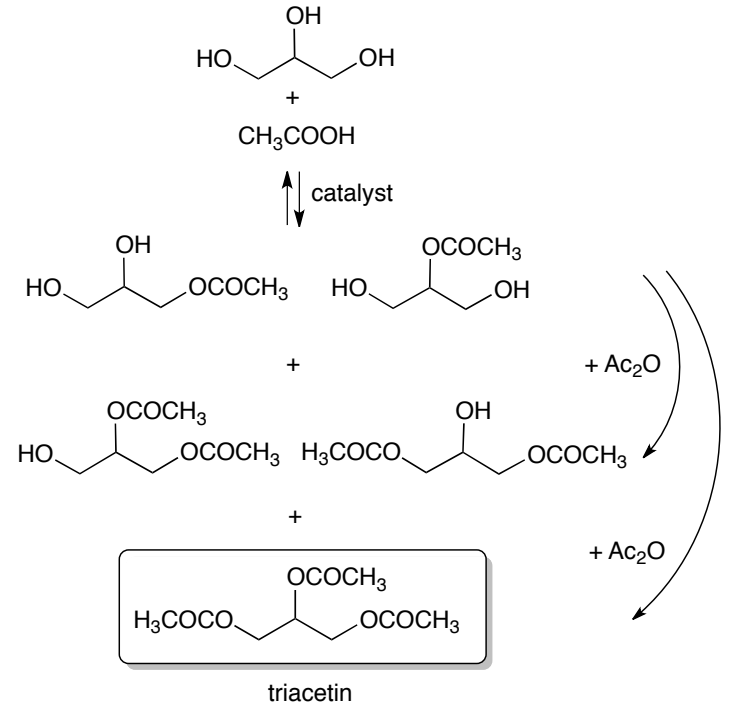

Scheme 27 Synthesis of triacetin in a two-step reaction
Some other methods are based on transesterification reactions either of triglycerides ${ }^{83}$ or glycerol with methyl acetate. ${ }^{84}$ In the first case, enzymatic catalysis is used and triacetin is obtained in ca. $80 \%$ yield as a by-product of fatty acid methyl esters

30 (biodiesel). In the second case, several solid acid catalysts have been tested. Although high conversions of glycerol are achieved, yields of triacetin are under $20 \%$.

\section{Properties}

The use of acylglycerols as solvents is almost limited to those 35 compounds possessing esters moieties with 1 to 4 carbon atoms. The length of the ester chain and the glycerol functionalization (mono, di or triacylglycerols) are used to tune the properties of these compounds such as biodegradability, water miscibility, boiling point, etc. For instance, triacetin is readily biodegradable 40 in activated sludge. This chemical is stable to hydrolysis in water at $\mathrm{pH} 4$, whereas it is hydrolyzed at $\mathrm{pH} 7$ and $\mathrm{pH} 9$ with half-lives of 60.4 days and 16.5 hours at $25^{\circ} \mathrm{C}$, respectively.

Table 4 gathers the lower and upper values of some interesting properties of these compounds.

45 Table 4 Physico-chemical properties of glycerol esters

\begin{tabular}{|c|c|c|}
\hline Property & $\begin{array}{l}\text { Lower value } \\
\text { (compound) }\end{array}$ & $\begin{array}{l}\text { Upper value } \\
\text { (compound) }\end{array}$ \\
\hline $\begin{array}{l}\text { Density } \\
\left(\mathrm{g} \mathrm{mL}^{-1}\right)\end{array}$ & $\begin{array}{c}1.05 \\
\text { (tributyrin) }\end{array}$ & $\begin{array}{c}1.22 \\
\text { (monoacetin) }\end{array}$ \\
\hline $\begin{array}{l}\text { Boiling point } \\
\qquad\left({ }^{\circ} \mathrm{C}\right)\end{array}$ & $\begin{array}{c}253 \\
\text { (monoacetin) }\end{array}$ & $\begin{array}{c}307 \\
\text { (tributyrin) }\end{array}$ \\
\hline $\begin{array}{l}\text { Water solubility } \\
\qquad\left(\mathrm{g} \mathrm{L}^{-1}\right)\end{array}$ & $\begin{array}{c}0.28 \\
\text { (tributyrin) }\end{array}$ & $\begin{array}{c}456 \\
\text { (monoacetin) }\end{array}$ \\
\hline $\begin{array}{l}\text { Vapor pressure } \\
\text { (Torr) }\end{array}$ & $\begin{array}{l}1.98 \times 10^{-5} \\
\text { (dibutyrin) }\end{array}$ & $\begin{array}{c}1.4 \times 10^{-2} \\
\text { (triacetin) }\end{array}$ \\
\hline $\log P$ & $\begin{array}{c}0.80 \\
\text { (monoacetin) }\end{array}$ & $\begin{array}{c}3.16 \\
\text { (tributyrin) }\end{array}$ \\
\hline
\end{tabular}

${ }^{a}$ Source SciFinder ${ }^{\circledR}$. Values calculated using Advanced Chemistry Development (ACD/Labs).

The use of glycerol-derived esters as solvents in formulations 50 often requires the study of their binary phase behavior. Such kinds of studies have already been carried out for triacylglycerols ${ }^{85}$ and 1,3-diacylglycerols. ${ }^{86}$

\section{Applications}

There is an extended use of acylglycerol in industrial 55 applications, above all of triacylglycerols. For instance, ca. twenty new applications appeared monthly for triacetin in the last months. Extraction media, vehicle for drug delivery systems, plasticizers or additives in animal feeds can be cited among the more general industrial uses for acylglycerols. We present here 60 some specific examples.

Thus, monoglycerides with ester moieties from 1 to 7 carbon atoms have been used as solvents in antibacterial or anti-mould formulations ${ }^{87}$ as well as cellulose plasticizers. ${ }^{88}$

The use of monoacylglycerols (monoacetin, monopropionin and ${ }_{65}$ monobutyrin) and diacylglycerols (diacetin, dipropionin and dibutyrin) as industrial solvents is very scarce, however triacylglycerols have been massively used. Thus, triacetin has been used as solvent for caffeine extraction from coffee or tea, ${ }^{89}$ as well as in ceramic preparation via enzymatic catalysis acting as $70 \mathrm{a} \mathrm{pH}$ regulator when hydrolyzed in the reaction media. ${ }^{90,91}$ 
Most of the uses of tripropionin in industry are closely related to the other triacylglycerols but its lower solubility in water compared to that of triacetin makes it very suitable as solvent for water extraction. An interesting example is the use of tripropionin 5 for the extraction of organic compounds from fermentation media. $^{92}$

Finally, tributyrin plays a relevant role in pharmaceutical applications. It has been used both as carrier or solvent and as active agent in drug formulations ${ }^{93-96}$ or as angiogenic material. ${ }^{97}$

10 Acylglycerols have also been described as reaction media but to a lesser extent. Again triacetin is the preferred solvent, although in this case some examples can be found in which diacetin and tributyrin have also been used.

An interesting work is the one described by Wolfson and co${ }_{15}$ workers, ${ }^{15}$ in which glycerol, diacetin, triacetin and tributyrin have been compared to water, 1,2- and 1,3-propanodiol in three characteristic organic reactions, such as a nucleophilic substitution, a Suzuki cross-coupling reaction and an enzymatic asymmetric reduction (Scheme 28).

nucleophilic substitution

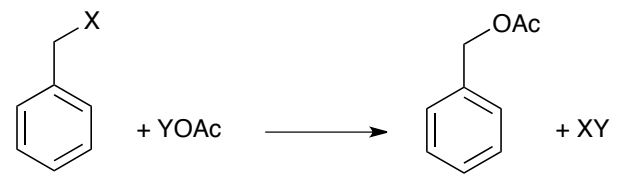

Suzuki cross-coupling

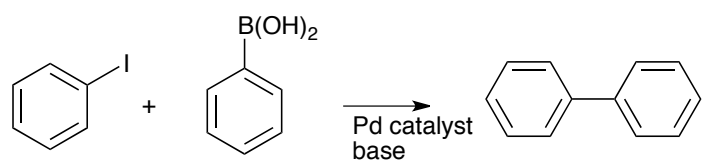

reduction

$$
\stackrel{\text { Baker's yeast }}{\longrightarrow}
$$

Scheme 28 Selected reactions for the assay of glycerol-derived solvents

The nucleophilic substitution on benzylic halides requires the dissolution of an organic compound and an ionic salt, so it is expected that the polarity of the solvent influence the reaction

25 results. In this case, the best conversions are obtained in glycerol and 1,2-propanediol, moderate yields are described with diacetin, and in triacetin the reaction does not take place at all.

The Suzuki cross-coupling reaction is normally carried out in a polar organic solvent able to dissolve both reactants. As in the 30 case of nucleophilic substitution, the polarity of the glycerol derivative strongly influences the reaction yields. Thus, the best results were obtained with the more polar derivatives (glycerol $>$ diacetin $>$ triacetin), but in this case reaction in triacetin reached $70 \%$ yield, and this compound turned out to be better than 1,235 propanediol for product extraction.

Finally, the asymmetric reduction of carbonyl compounds using baker's yeast as catalyst and acylglycerols as solvents was also studied. In this case the viability of the cells in the reaction media must also be considered. Very high enantioselectivities (97
${ }_{40} \%$ ee) and moderate yields $(50 \%)$ were obtained in triacetin and tributyrin, while reaction did not take place in diacetin. Cell viability was longer in triacetin (48h) than in tributyrin (4h) and in more polar solvents such as diacetin or glycerol cell viability was reduced to a few minutes.

45 Triacetin as also been described as solvent and acyl donor in the synthesis of isoamyl acetate ${ }^{98,99}$ catalyzed by lipase CALB or Amberlyst 36 (Scheme 29). In both cases the use of triacetin as reaction media allows high conversions in the transesterification reaction and an easy separation of the product and the catalyst s0 (Table 5).

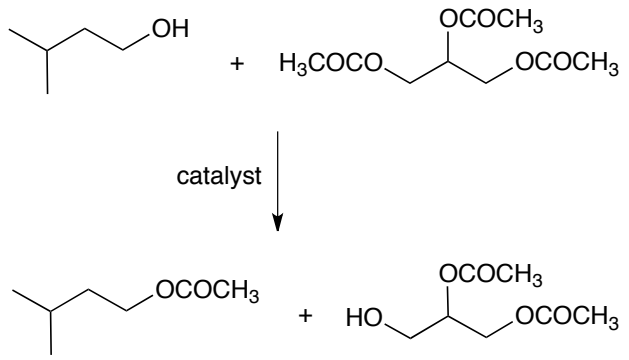

Scheme 29 Synthesis of isoamylacetate by transesterification reaction with triacetin

Table 5 Results in the synthesis of isoamyl acetate using triacetin as 55 solvent

\begin{tabular}{lcc}
\hline \multicolumn{1}{c}{ catalyst } & run & Conversion (\%) \\
\hline Amberlyst 36 & 1 & 97 \\
& 2 & 85 \\
Immobilized CAL B & 3 & 60 \\
& 1 & 73 \\
& 2 & 71 \\
& 3 & 71 \\
\hline
\end{tabular}

Triacetin has also been used in the one-pot synthesis of cinnamyl acetate from cinnamaldehyde. ${ }^{100}$ This process consist in a tandem reaction using two catalyst: first baker's yeast for 60 carbonyl reduction and then Amberlyst 36 for transesterification reaction (Scheme 30). Again high conversions and selectivities were achieved with the main advantage of an easy product and catalyst recoverability and solvent recycling.<smiles>O=C/C=C/c1ccccc1</smiles>

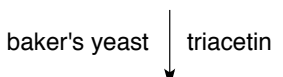

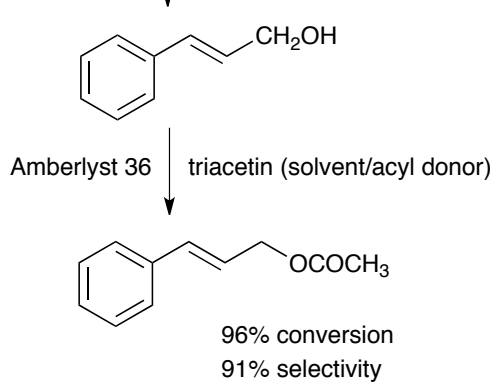

Scheme 30 Synthesis of cinnamyl acetate in triacetin

Another example of the use of triacetin as reaction media is the 
production of paclitaxel ${ }^{101}$, an anticancer drug, by cell culture of the plant of the genus Taxus. In this case, adition of triacetin to the culture tank remarkably increased the productivity of the active agent.

\section{${ }_{5}$ Glycerol carbonate}

Glycerol carbonate (GC) is already an industrial common product, commercially available, with applications in many industrial processes. Very recently, a deep critical review about glycerol carbonate as a versatile building block for tomorrow 10 have been published by Sonnati et al. ${ }^{102}$ We refer the interested readers to that review in order to know detailed information about the synthesis, reactivity, properties and applications of glycerol carbonate. In the present paper we will mainly focus on those publications appeared since the above-mentioned review.

\section{${ }_{15}$ Synthesis}

There are several general procedures to prepare glycerol carbonate from glycerol, either directly or through reactive intermediates, such as chlorohydrins or glycidol. The principal synthetic routes are outlined in Scheme 31. More details on these ${ }_{20}$ general procedures are available in ref. 102.

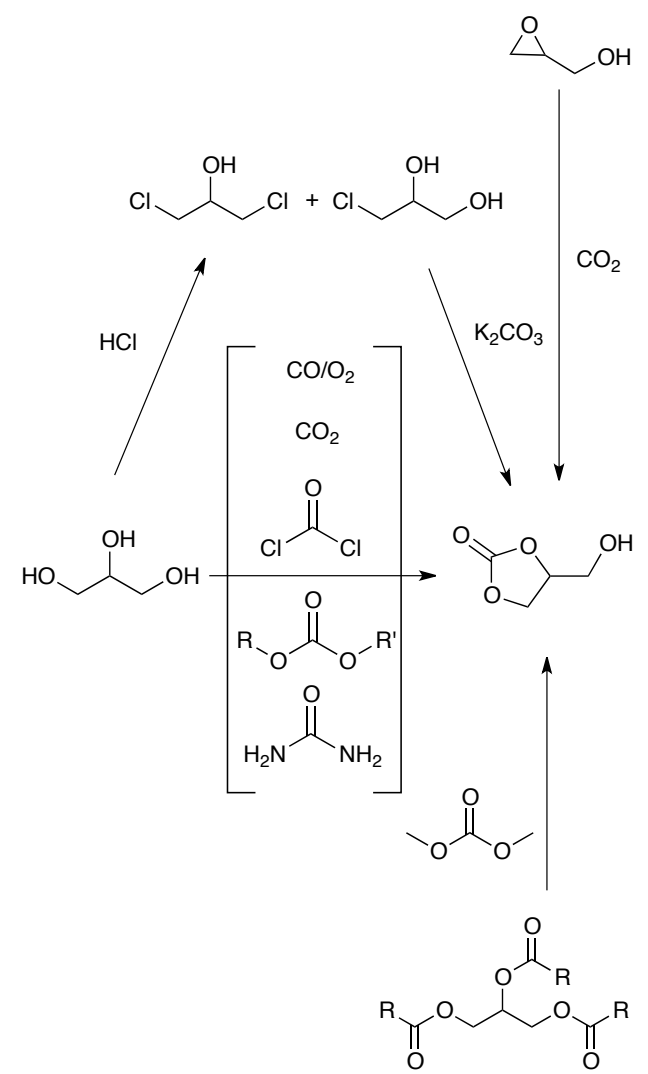

Scheme 31 General procedures for the synthesis of glycerol carbonate from glycerol

Au-Pd nanoparticles have been reported as very effective 25 catalysts for the transformation of glycerol into glycerol carbonate using a recycling cycle of urea in the chemical fixation of carbon dioxide with an excellent activity ( $87 \%$ yield), selectivity $(77 \%)$ and recoverability (9 times). ${ }^{103}$
Zinc-containing solid catalysts (zinc oxide, smectite, 30 hydrotalcite) and several inorganic zinc salts have been used to produce glycerol carbonate from glycerol and urea. Some of them have shown excellent conversions (82-92\%) and excellent selectivity $(80-92 \%)$. The true heterogeneous nature of these catalysts has been investigated, and a correlation between 35 carbonate yields and the amount of zinc species dissolved into the liquid phase has been observed. This fact is explained by the leaching of $\mathrm{Zn}$ species from the solid catalysts. The authors of this work conclude that the reaction takes place homogeneously in the liquid phase irrespective of the parent solid catalysts 40 used. ${ }^{104}$

A series of $\mathrm{M} / \mathrm{MgO}\left(\mathrm{M}=\mathrm{CaO}, \mathrm{KNO}_{3}, \mathrm{KOH}, \mathrm{K}_{2} \mathrm{CO}_{3}\right)$ have been described as cheap and no toxic heterogeneous catalysts for the synthesis of glycerol carbonate from glycerol and dimethyl carbonate without additional solvents. The authors described

${ }_{45} \mathrm{~K}_{2} \mathrm{CO}_{3} / \mathrm{MgO} 1 \%$ wt as the most efficient catalyst, with a glycerol carbonate yield of approximately $99 \%$. This catalyst could be regenerated and reused at least up to four times. ${ }^{105}$

Magnesium-lanthanum mixed oxides have also been used as catalysts for the transesterification of dimethyl carbonate with 50 glycerol, although only moderate conversions were obtained. ${ }^{106}$ Polymeric monoglycerolate complexes of zinc and cobalt have been described as homogeneous catalysts for the one-pot synthesis of glycerol carbonate from glycerol and urea, with yields reaching $83 \%$ at $98 \%$ glycerol conversion. ${ }^{107}$

55 A new strategy has been described to produce glycerol carbonate by using a cross-linked enzyme aggregate onto magnetic particles (CLEMPA). ${ }^{108}$ The CLEMPA with the lipase enzyme from Aspergillus niger catalyzed the conversion of glycerol to glycerol carbonate with dimethyl carbonate in solvent-

${ }_{60}$ free conditions. An encouraging biocatalytic performance with $61 \%$ glycerol conversion and $90 \%$ selectivity was obtained. Furthermore, the results were reproducible by using "crude" glycerol extracted from the biodiesel process. The catalyst was easily recovered and reused for 20 successive reaction cycles, ${ }_{65}$ demonstrating the robustness of the prepared CLEMPA structure. ${ }^{108}$

\section{Applications}

The activity of biocatalysts in non-aqueous solvents has been investigated, ${ }^{109}$ the behavior of proteins resulting greatly affected 70 by the solvent. One of the advantages of glycerol carbonate in this context is that its ionizing and dissociating abilities are very close to those of water, preventing protein denaturation. 


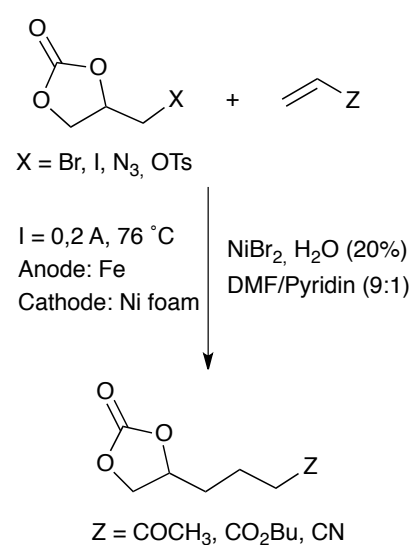

Scheme 32 Glycerol carbonate as nucleophile in conjugate additions catalyzed by nickel

Apart from its use as solvent, glycerol carbonate can be also 5 used as a reagent. Thus, an efficient (98-100\% yield) solvent-free synthesis of a variety of highly pure 1,3-sn-diacylglycerols has been recently proposed. ${ }^{110}$ As previously mentioned, these products are popular in the food industry as benign low hydrophilic-lipophilic balance (co)emulsifiers, rheological 10 modifiers and dietary fat and oils.

Glycerol carbonate has also been used as reagent in conjugate addition reactions catalyzed by nickel complexes (Scheme 32). ${ }^{111}$ This is the first example of using glycerol carbonate in carboncarbon bond formation reactions.

\section{${ }_{15}$ Glycerol acetals and ketals}

An easy way to obtain glycerol derivatives with potential properties as solvents is the condensation with aldehydes or ketones for the obtaining of acetals or ketals (Scheme 33). The synthesis and use of glycerol ketals and acetals was firstly ${ }_{20}$ reviewed by Showler and Darley in $1967 .{ }^{112}$

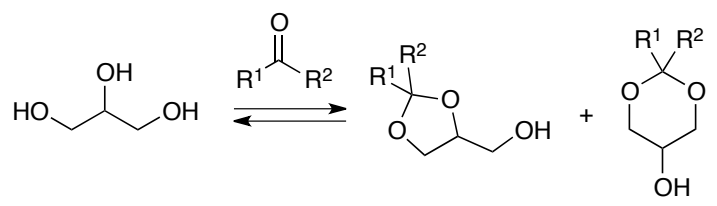

Scheme 33 Synthesis of glycerol ketals

Acetals and ketals formation from glycerol is an equilibrium that is commonly catalyzed by acids. Sulfuric acid or $p$ 25 toluenesulfonic acid are the most used catalysts in homogeneous phase, ${ }^{113}$ although problems of separation and partial loss of the products during the reaction treatment could occur due to the solubility in water of some of the glycerol ketals and acetals.

For this reasons, efforts have been devoted to find more suitable 30 catalysts for these reactions among the most traditional heterogeneous acid catalysts.

Although we are aware that several catalytic systems such $\mathrm{SnO}_{2}$ doped with Mo or $\mathrm{W},{ }^{114} \mathrm{CpIrCl}_{2}{ }^{115}$ or Re complexes, ${ }^{116}$ and Ti exchanged montmorillonite ${ }^{117}$ have been used for glycerol 35 acetal and ketal formation, here we will just focus our review on the works dealing with the synthesis of glycerol formal or solketal, due to its widespread use as solvents.
The reaction of glycerol with formaldehyde provides two possible ketals, a 5-membered cyclic ketal (4-hydroxymethyl-1,340 dioxolane) and a 6 membered cyclic one (5-hydroxy-1,3-dioxane) (Scheme 34). The mixture of both products is called glycerol formal.

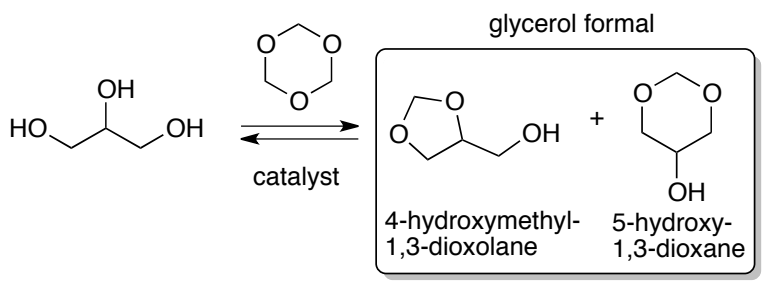

Scheme 34 Synthesis of glycerol formal from glycerol condensation with formaldehyde

The influence of several reaction parameters in the ratio of 5hydroxy-1,3-dioxane and 4-hydroxymethyl-1,3-dioxolane obtained in the condensation reaction of glycerol with formaldehyde using heterogeneous catalysts such as Ambelyst 50 36, Nafion NR 50, Montmorillonite K10 and H-BEA has been investigated. ${ }^{118}$ The best results concerning yield and selectivity were achieved using Amberlyst 36 as catalyst (74\% yield and $78 \%$ selectivity towards 5-hydroxy-1, 3-dioxane).

Several zeolites have been used for the synthesis of glycerol ${ }_{55}$ formal. ${ }^{119}$ Zeolite Beta appeared to be the most adequate catalyst; $95 \%$ yield was achieved in 60 min reaction time with $70 \%$ selectivity towards the 6-membered cyclic ketal. Recently Corma and co-workers ${ }^{120}$ described the use of a recoverable gold complex, a mild Lewis acid catalyst, for glycerol formal 60 synthesis, $90 \%$ yields and $72 \%$ selectivity towards 5-hydroxy1.3-dioxane were obtained in very mild reaction conditions.

Solketal is obtained by condensation of glycerol with acetone (Scheme 35). In this case only 5-membered cyclic ketal is obtained regardless the catalyst used and the reaction conditions.

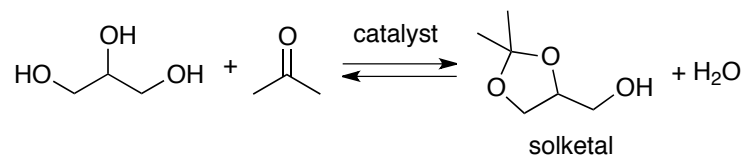

Scheme 35 Syntesis of solketal by glycerol condensation with acetone

Several solids have been described as efficient heterogeneous catalysts for this reaction. Table 6 gathers the most promising results published up to now.

70 Table 6 Results in the synthesis of solketal catalyzed by solid acids

\begin{tabular}{|c|c|c|c|c|}
\hline Catalyst & $\begin{array}{l}\text { Reaction } \\
\mathrm{T}\left({ }^{\circ} \mathrm{C}\right)\end{array}$ & $\begin{array}{l}\text { Acetone/glycerol } \\
\text { ratio }\end{array}$ & $\begin{array}{l}\text { Solketal } \\
\text { yield }\end{array}$ & ref \\
\hline Amberlyst 36 & 25 & $1.5 / 1$ & 88 & 118 \\
\hline Amberlyst 15 & 70 & $6 / 1$ & 85 & 121 \\
\hline Ar-SBA-15 & 70 & $6 / 1$ & 82 & 121 \\
\hline $\mathrm{TiO}_{2}-\mathrm{SiO}_{2}$ & 70 & $4 / 1$ & 90 & 122 \\
\hline Hf-TUD & 80 & $2 / 1$ & 64 & 123 \\
\hline Zr-TUD & 80 & $2 / 1$ & 65 & 123 \\
\hline Sn-MCM41 & 80 & $2 / 1$ & 62 & 123 \\
\hline
\end{tabular}

Solketal synthesis can be optimized by shifting the equilibrium towards the ketal formation either by using a larger excess of acetone (which can be easily removed after reaction by 
distillation) or by removing water from the reaction medium. The first option has been accomplished by using a molar ratio of 20/1 of acetone/glycerol and K10-montmorillonite as a cheap and reusable catalyst. 95\% yield of solketal was achieved in these 5 conditions. ${ }^{124}$ The option of removing water from the reaction media was explore by Melero and co-workers, ${ }^{121}$ who managed to reach $80-90 \%$ glycerol conversion using Ar-SBA15 as catalyst and a reaction system consisting of three consecutive 2-step batches (30 min under reflux and an evaporation step under 10 vacuum). Another example of this strategy is that reported by Fraile and co-workers, ${ }^{125}$ who proposed the combination of K10montmorillonte as solid catalyst and the use of a zeolitic membrane for water separation. In this way, yields of solketal above $90 \%$ are achieved with little excess of acetone. Another 15 possibility is tuning the hydrophobicity of the solid catalyst in order to take water away from the catalytic sites. ${ }^{119}$ In this approach, the most hydrophobic solid, zeolite Beta, provided the best results in terms of ketal yields, compared to more hydrophilic solids such as K10-montmorillonite, zeolite ZSM5 or 20 zeolite USY.

Finally, the synthesis of glycerol ketals using ketones with longer alkyl chains, ${ }^{126,124}$ or with the remaining hydroxyl group protected by etherification ${ }^{118}$ or esterification reactions ${ }^{124,127}$ has 25 also been described. The interest of these derivatives is the possibility of tuning the polarity of the product, which should be interesting from the point of view of their utility as solvents.

\section{Properties}

Solketal is a colorless and odorless liquid, completely soluble in 30 water. It has a density of $1.063 \mathrm{~g} \mathrm{~mL}^{-1}$, boiling point of $188^{\circ} \mathrm{C}$, a viscosity $11 \mathrm{cP}\left(20{ }^{\circ} \mathrm{C}\right)$ and a low vapor pressure at $25{ }^{\circ} \mathrm{C}$ (estimated value $=0.16$ Torr), and possesses a $\mathrm{LD}_{50}=7 \mathrm{~g} \mathrm{~kg}^{-1}$ according to the providers material safety data sheet.

Some interesting parameters for its use as solvent have been 35 determined by García et al. ${ }^{128}$ Thus its hydrogen bond donor ability is typical for those of aliphatic alcohols. Its polarity is between the one of acetonitrile and ethanol and its hydrophobicity between the one of ethanol and 2-propanol. ( $\log \mathrm{P}$ $\left.=0.03, E_{T}^{N}=0.62\right) .{ }^{128,129}$

40 Glycerol formal is a viscous colorless liquid with very little odor. It is soluble in water, chloroform, acetone and low molecular weight alcohols and ethers. It has a density of $1.235 \mathrm{~g}$ $\mathrm{mL}^{-1}$, boiling point of $192-193^{\circ} \mathrm{C}$, flash point at $98^{\circ} \mathrm{C}$ and $\log \mathrm{P}=$ $-0.53,{ }^{129}$ and it possesses a $\mathrm{LD}_{50}=8 \mathrm{~g} \mathrm{~kg}^{-1}$, according to the ${ }_{45}$ providers material safety data sheet.

\section{Applications}

Acetals and ketals derived from glycerol can be used as intermediates for the synthesis of platform molecules such as hydroxyacetone or 1,3-propanediol, or as additives to fuel to 50 reduce hydrocarbon emission or to biodiesel to improve the cold flow properties, but here we are mostly interested in the use of these glycerol derivatives as solvents.

Glycerol formal and solketal have been widely used as solvents in several large-scale applications such as in paint and 55 ink formulations, ${ }^{130}$ cleaning products ${ }^{131-133}$ or in cooling agents. ${ }^{134}$ In the pharmaceutical industry, they have been used as additive for injectables, ${ }^{135-139}$ as vehicle for drugs in topical uses $^{140}$ or in controlled delivery systems. ${ }^{141,142}$

Glycerol formal and solketal have also been described as an ${ }_{60}$ efficient media for liquid formulation of neonicotinoid pesticides $^{143,144}$ and ectoparasiticides containing metaflumizone and amitraz ${ }^{145}$ or isoxazolines ${ }^{146}$ as active agents.

The use of glycerol formal or solketal as reaction media is very limited due to their scarce stability in acidic conditions, although ${ }_{65}$ they can be used in neutral or basic media. Studies of stability of both compounds towards acid hydrolysis have been carried out by Mota and co-workers, in which solketal has been proven to be less stable than glycerol formal. ${ }^{147}$

An interesting example of their use as solvent is the change in 70 regioselectivity observed when using solketal in the synthetic behavior of Biolacta $\beta$-galactosidase. ${ }^{129}$ With these solvents the enzyme changes its well known tendency to produce $\beta-(1 \rightarrow 4)$ disaccharides, leading preferentially to $\beta-(1 \rightarrow 6)$ disaccharides.

Glycerol formal has been used as co-initiator for 75 polymerization and as reaction media. ${ }^{148,149}$ It has been proved to be a good substitute for methylisobutylketone in the preparation of active pharmaceutical ingredients such as of loperamide or pimozide (Scheme 36$).{ }^{150}$

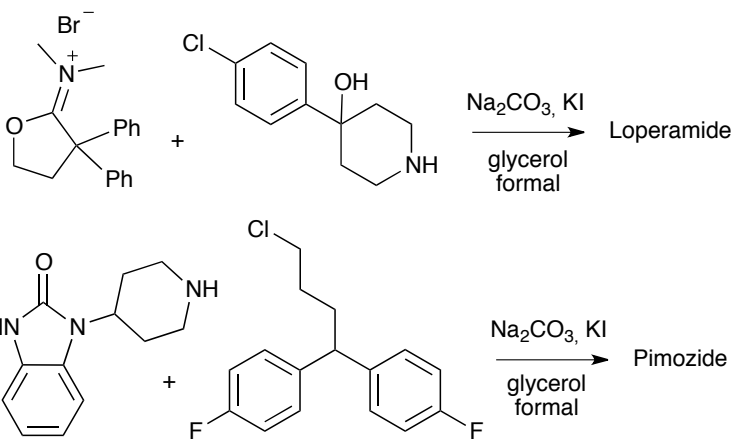

80 Scheme 36 Synthesis of loperamide and pimozide using glycerol formal as solvent

Finally, the use of solketal and glycerol formal as solvent for isolation of nucleic acids has also been described, by adsorbing a nucleic acid onto a solid phase, such as a substrate with a silica ${ }_{85}$ surface, ${ }^{151}$ or as an eluent in the separation of target molecules from complex solutions by column chromatography. ${ }^{152}$

\section{Glycerol ethers}

\section{Synthesis}

Some glycerol ethers, such as glycidyl tributyl ether (GTBE), 90 have been widely used as fuel additives. For this reason they have been massively produced in the industry. The industrial treatment of sodium glycerate with dimethyl sulfate leads to mixtures of (glycidyl monomethyl ethers (GMMEs), glycidyl dimethyl ethers (GDMEs) and glycidyl trimethyl ether (GTME) in good yields, ${ }_{95}$ over $\left.93 \%\right) .{ }^{153}$ Very recently, a patent has been applied for to protect both the synthesis and the applications of 1,2,3trimethoxypropane (Scheme 37). ${ }^{154}$ 


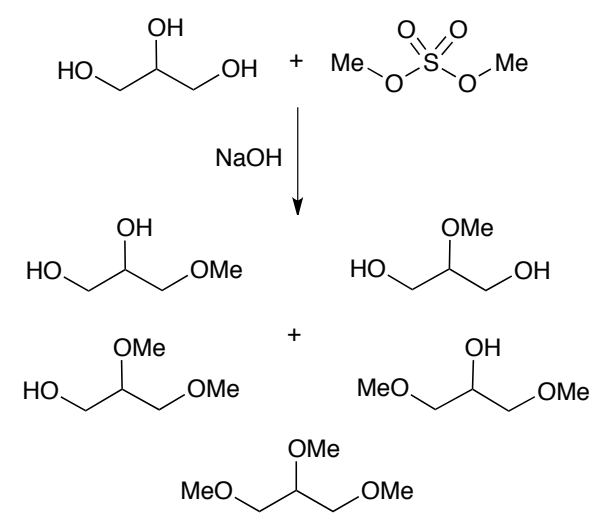

Scheme 37 GMMEs, GDMEs, and GTME production from glycerol

A review of the state of the art about the etherification reaction of glycerol with light olefins (isobutene, isoamylenes), by using 5 strong acid ion-exchange resins has appeared recently. ${ }^{155}$

Furthermore, several heterogeneous catalysts, such as different zeolites and montmorillonite $\mathrm{K} 10$, all of them sulfonated under microwaves activation, have proven to be successful catalysts in the synthesis of glycerol di- and triethers, where the best catalyst 10 gave a total conversion and $91 \%$ selectivity to GTBE (Scheme 38). ${ }^{156}$ The telomerization of butadiene in an aqueous biphasic system in the presence of palladium complexes as catalysts, also yields glycerol ethers. ${ }^{157}$

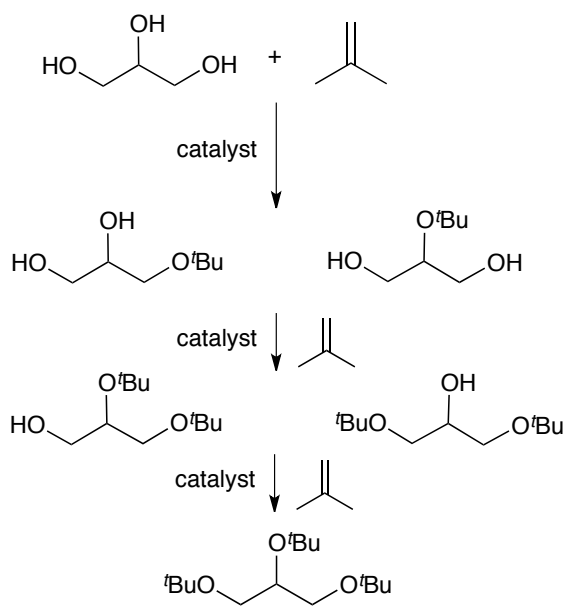

Scheme 38 Glycerol tert-butylethers production from glycerol

1-O-alkyl(di)glycerol ethers have been obtained by using two different pathways with excellent conversion and selectivity (Scheme 39). The first one used biosourced methyl esters to carry out a reductive alkylation with (di)glycerol under $5 \mathrm{MPa}$ 20 hydrogen pressure in the presence of $1 \mathrm{~mol} \%$ of $\mathrm{Pd} / \mathrm{C}$ and an acid co-catalyst. The second one, a two step procedure is used, consisting of transesterification to the corresponding monoglyceride with a $\mathrm{BaO} / \mathrm{Al}_{2} \mathrm{O}_{3}$ catalyst, followed by reduction with a recyclable heterogeneous catalytic system $(\mathrm{Pd} / \mathrm{C}$ and ${ }_{25}$ Amberlyst 35) under $\mathrm{H}_{2}$ pressure. ${ }^{158,159}$ The same researchers had previously developed an analogous system to obtain (poly)glycerol monoethers. ${ }^{160}$

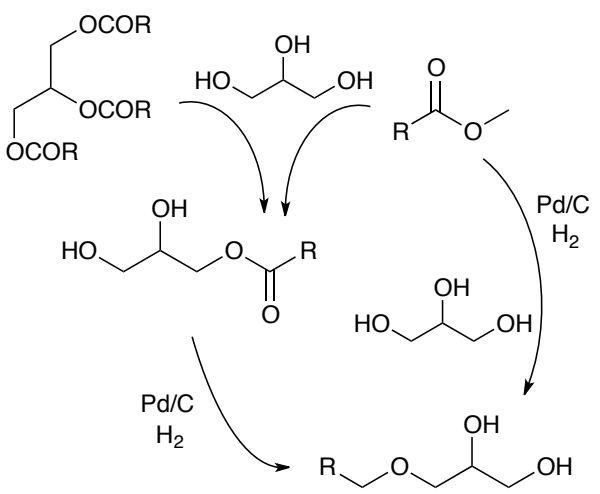

Scheme 39 Synthesis of glycerol monoethers by reductive alkylation of glycerol or by two step (transesterification and reduction) system

Different homogeneous alkali catalysts $(\mathrm{LiOH}, \mathrm{NaOH}, \mathrm{KOH}$ and $\mathrm{Na}_{2} \mathrm{CO}_{3}$ ) have been used to carry out the synthesis of oxygenated fuel additives via solvent free-base catalyzed etherification of glycerol, with moderate conversions and low ${ }_{35}$ selectivities. ${ }^{161}$ Results were improved by using an heterogeneous catalyst, based on K10-montmorillonite and $\mathrm{LiOH}$, which improved the results obtained. ${ }^{162}$

A design of 24 experiments to optimize the control of three variables (temperature, catalyst and type of solvent) in the 40 etherification of glycerol has been developed by using tert-butyl alcohol and a solid acid catalyst. ${ }^{163}$ There is a high industrial interest in this reaction, and for this reason kinetic models have been profusely developed. ${ }^{164}$ The design, economics, and control of a glycerol-tert-butyl alcohol etherification plant have been 45 reported. ${ }^{165}$

The direct catalytic etherification of glycerol with 1-dodecanol in presence of 1-bromododecane has been described for the first time, leading to moderate yields $(<60 \%)$ (Scheme 40$).{ }^{166}$ This work opens the way to a direct route for the synthesis of bio${ }_{50}$ based surfactants

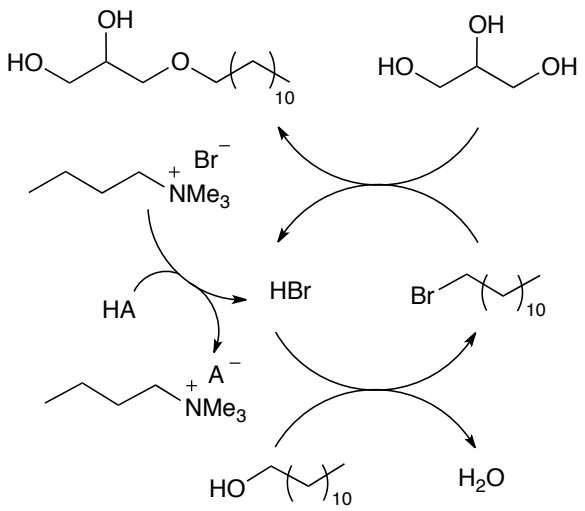

Scheme 40 Catalytic etherification of glycerol with 1-dodecanol

Although aryl derivatives are less interesting from the point of view of solvent applications, glycerol has also been arylated. For 55 instance, the selective transformation of glycerol into mixtures of aryloxypropanediols has been accomplished in a one-pot reaction under benign and solvent-free conditions, where catalyst and unreacted reagent could be recycled (Scheme 41). ${ }^{167}$ 


\section{Instituto de Sintesis Química y Catálisis Homogénea}
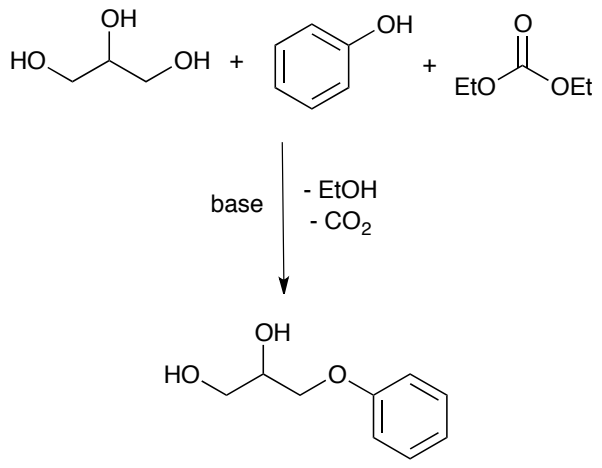

Scheme 41 Selective transformation of glycerol into aryloxypropanediols

The acid-catalyzed etherification of glycerol with 1phenylethanol has been carried out by using different types of 5 heteropolyacids supported on hexagonal mesoporous silica and K10-montmorillonite as catalysts, which were highly active and selective. ${ }^{168}$

Another possibility is getting glycerol ethers indirectly from glycerol. Glycerol can be transformed first into more reactive 10 intermediates, which can in turn be used to obtain the desired ethers. One of these intermediates is glycidol, ${ }^{169,170}$ which can in turn be obtained from glycerol carbonate. For instance, ionic liquids catalyze the decarboxylation of glycerol carbonate to produce glycidol. The production of glycidol improved by 15 addition of a zinc salt in the medium $(98 \%) .{ }^{171}$ The intensification of glycidol production is a very important issue, and hence a solvent-free transformation of glycerol carbonate into glycidol under mild conditions has been described, using ZSM-5 zeolite and a zinc oxide-supported with the highest selectivity to glycidol $20(>99 \%)$ from glycerol carbonate at high conversion values (71\%). ${ }^{172}$ Another reactive intermediate that can be prepared from glycerol is epichlorohydrin. ${ }^{173-176}$

Both epoxides can be transformed into glycerol ethers by an alcoholic ring opening of the oxirane (Scheme 42). There are

25 different catalyst to carry out the oxirane ring opening, such as alumina, ${ }^{177}$ magnesium hydrogen sulfate, ${ }^{178} \mathrm{Sn}-\mathrm{P},{ }^{179}$ and ceric ${ }^{180}$ or aluminum ${ }^{181}$ dodecatungstophosphate.

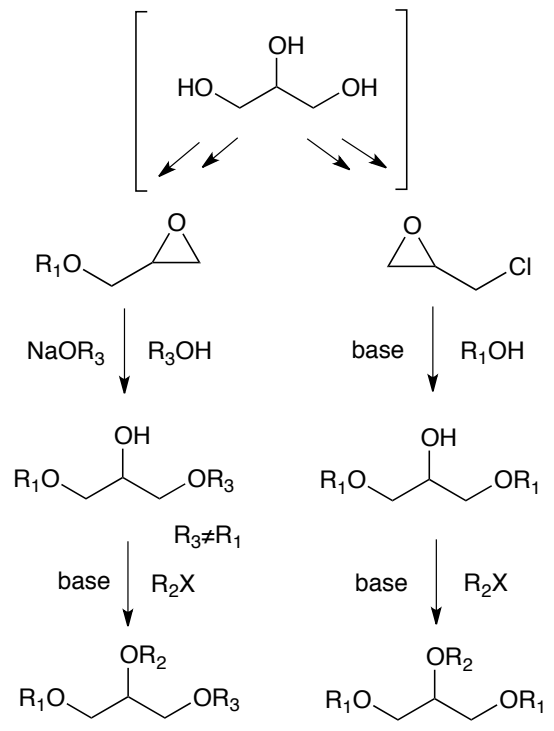

Scheme 42 Several steps glycerol transformation to glycerol alkyl ethers

30 The use of $\mathrm{Mg} / \mathrm{Al}$ mixed oxides as base catalysts for the etherification of glycerol has also been investigated. ${ }^{182}$ These solids have shown to be active in the formation of polyglycerols from glycerol without solvents, at $220^{\circ} \mathrm{C}$ in a batch reactor.

\section{Properties}

${ }_{35}$ Regarding their properties, glycerol ethers may be classified in two subgroups, protic glycerol ethers, comprising both 1-alkoxy2,3-propanodiols and 1,3-dialkoxy-2-propanols, and non-protic ethers, consisting of 1,2,3-trialkoxypropanes.

Protic glycerol ethers ${ }^{183}$

40 They are moderately to low viscous solvents: 1-alkoxy-2,3propanodiols have viscosities from 35 to $42 \mathrm{cP}$, whereas 1,3dialkoxy-2-propanols have viscosities from 3 to $20 \mathrm{cP}$, measured at $25{ }^{\circ} \mathrm{C}$. Some of them are water miscible and their densities fall within typical values for organic substances in the range of $0.9-$ ${ }_{45} 1.6 \mathrm{~g} \cdot \mathrm{mL}^{-1}$. Their boiling points are higher than $170{ }^{\circ} \mathrm{C}$ and their vapor pressures lower than 0.4 Torr at $25^{\circ} \mathrm{C}$. In this regard they can be considered as non-VOC solvents. Concerning polarity, 1,3-dialkoxy-2-propanols are quite polar $\left(E_{T}^{N}\right.$ values from 0.37 to 0.70 ; $\varepsilon$ values from 5.1 to 21.9 ), which is normal for alcohols. 50 Moreover the presence of fluorinated substituents results in an increase of the corresponding $E_{T}^{N}$ values (Table 7).

Non-Protic glycerol ethers ${ }^{183}$

They are low viscous solvents (from 1 to $4 \mathrm{cP}$ measured at 25 ${ }^{\circ} \mathrm{C}$ ). Immiscible with water, their densities fall within typical ${ }_{55}$ values for organic substances in the range of $0.8-1.3 \mathrm{~g} \cdot \mathrm{mL}^{-1}$. Their boiling points are higher than $150{ }^{\circ} \mathrm{C}$ and, in most cases, the vapor pressures are lower than 0.5 Torr at $25^{\circ} \mathrm{C}$, so they can also be considered as non-VOC solvents. Concerning polarity, 1,2,3trialkoxypropanes are not highly polar $\left(E_{T}^{N}\right.$ values from 0.15 to ${ }_{60} 0.20$; $\varepsilon$ values from 4.7 to 13.8 ), which is normal for non-protic solvents like ethers. The presence of fluorinated substituents results in a particularly noticeable increasing of polarity, with $E_{T}^{N}$ values over 0.50 in spite of being formally non-protic solvents (Table 7).

65 Table 7. Physico-chemical properties of glycerol ethers

\begin{tabular}{cccc} 
& $\begin{array}{c}\text { Glycerol } \\
\text { monoalkylethers }\end{array}$ & $\begin{array}{c}\text { Glycerol } \\
\text { dialkylethers }\end{array}$ & $\begin{array}{c}\text { Glycerol } \\
\text { trialkylethers }\end{array}$ \\
\hline Density $\left(\mathrm{g} \cdot \mathrm{mL}^{-1)}\right.$ & $0.99-1.10$ & $0.9-1.6$ & $0.8-1.3$ \\
Boiling point $\left({ }^{\circ} \mathrm{C}\right)$ & $>220$ & $>170$ & $>150$ \\
Vapor pressure, & n.a. & $<0.4$ & $<0.5$ \\
$25^{\circ} \mathrm{C}($ Torr $)$ & $0.68-0.71$ & $0.37-0.61$ & $0.15-0.20$ \\
$E_{T}^{N}$ & $12.5-21.8$ & $5.1-12.9$ & $4.6-13.7$ \\
$\varepsilon(\mathrm{ESU})$ & $35-42$ & $3-20$ & $1-4$ \\
\hline Viscosity, $(\mathrm{cP})$ & & & \\
\hline
\end{tabular}

\section{Applications}

Due to their chemical stability, glycerol alkyl ethers have been used as solvents to carry out several reduction and oxidation reactions. On the one hand, they have been used to form biphasic 70 catalytic systems with azabis(oxazoline)-cobalt(II) complexes to carry out the enantioselective reduction of ethyl $(E)$-3-phenylbut2-enoate with $\mathrm{NaBH}_{4}$ (Scheme 43). These biphasic media allowed the recycling of the catalyst in 5 runs with $90-96 \%$ ee, performing far better than ionic liquids. ${ }^{184}$ 
Instituto de Síntesis Química y Catálisis Homogénea

$$
\text { up to 99\% yield and } 96 \% \text { ee }
$$

Scheme 43 Conjugated reduction of ethyl (E)-3-phenylbut-2-enoate catalyzed cobalt complexes

Very recently, the use of 1,2,3-trimethoxypropane as solvent 5 for the reduction of nitrile, nitro, ester, and acid functional groups using either aluminum hydride or 1,1,3,3-tetramethyldisiloxane (TMDS) has been described. ${ }^{185}$ The corresponding amines and alcohols are readily obtained in good yields by using TMDS as a benign hydride source and a copper catalyst (Scheme 44).

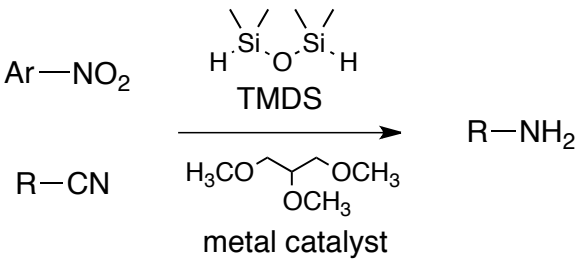

$$
\begin{aligned}
& \mathrm{R}-\mathrm{COOR}^{\prime} \longrightarrow \mathrm{R}-\mathrm{CH}_{2} \mathrm{OH} \\
& \mathrm{R}=\mathrm{alkyl}, \text { aryl } \\
& \mathrm{R}^{\prime}=\mathrm{H}, \mathrm{CH}_{3} \\
& \text { metal catalyst }=\mathrm{Fe}(\mathrm{acac})_{3}, \mathrm{VO}(\mathrm{O} \mathrm{Pr})_{3}, \operatorname{InBr}_{3}, \mathrm{Cu}(\mathrm{OTf})_{2}
\end{aligned}
$$

Scheme 44 Hydride reduction of different organic functions in 1,2,3trimethoxypropane

Glycerol alkyl ethers have resulted to be excellent green reaction media to develop alkene epoxidations with hydrogen 15 peroxide, catalyzed by 1,2-bis(3,5-bis(trifluoromethyl)phenyl)diselenide (Scheme 45). ${ }^{186}$ This catalytic system can be easily recovered and recycled, the glycerol ether phase remaining catalytically active after distilling the alkene oxide. ${ }^{187}$

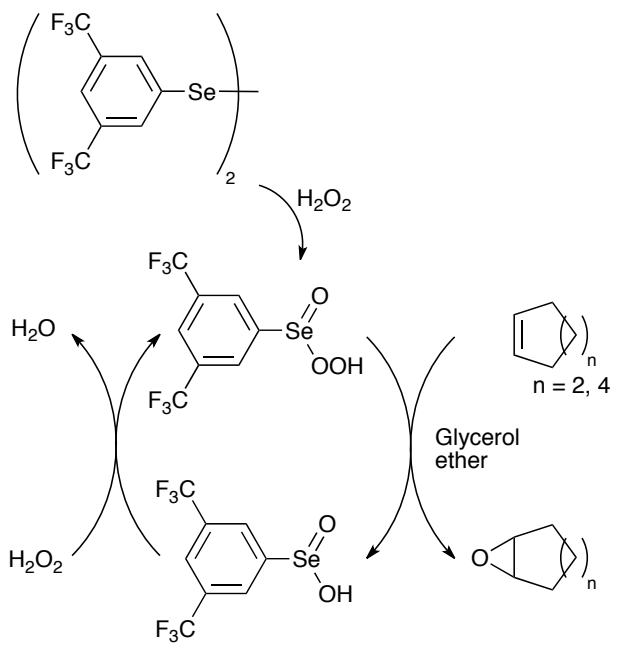

20 Scheme 45 Catalytic epoxidation with arylseleninic acid-hydrogen peroxide system

Some of these glycerol derivatives have been used as solvents in the epoxidation of fatty acid esters and biodiesel with $\mathrm{H}_{2} \mathrm{O}_{2}$, and they seem to play a double role in this process. On the one 25 hand, fluorine-bearing glycerol-derived solvents strongly accelerate the epoxidation reaction. On the other hand, some of them allow catalyst recycling. ${ }^{188}$

Furthermore they have also been used as neoteric solvents in the multiphase enantioselective Kharasch-Sosnovsky allylic 30 oxidation catalyzed by ditopic ligands-copper complexes (Scheme 46), yielding better results than ionic liquids. ${ }^{189}$

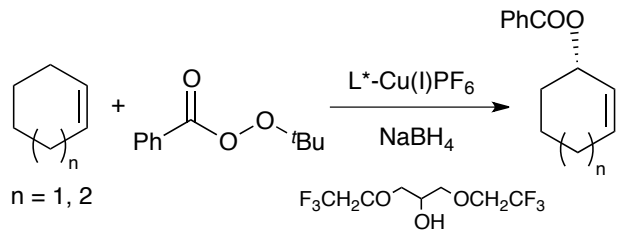

Scheme 46 Enantioselective Kharasch-Sosnovsky reaction catalyzed by copper complexes

35 Very recently, the use of 1,2,3-trimethoxypropane as ligand for the ortholithiation of planar chiral ferrocenes has been described. ${ }^{190}$ Although the results obtained are similar to those of 12-crown-4, they are however much poorer than those obtained using diglyme and other related ethers.

40 Glycerol ethers have also been used as biosolvents in the synthesis of disaccharides with Escherichia coli $\beta$-galactosidase with yields of up to $97 \%$ (Scheme 47). These reactions took place without noticeable hydrolytic activity and with total regioselectivity, which represents a considerable improvement 45 over the use of an aqueous buffer or conventional organic solvents. ${ }^{191}$ 
Instituto de Síntesis Químic
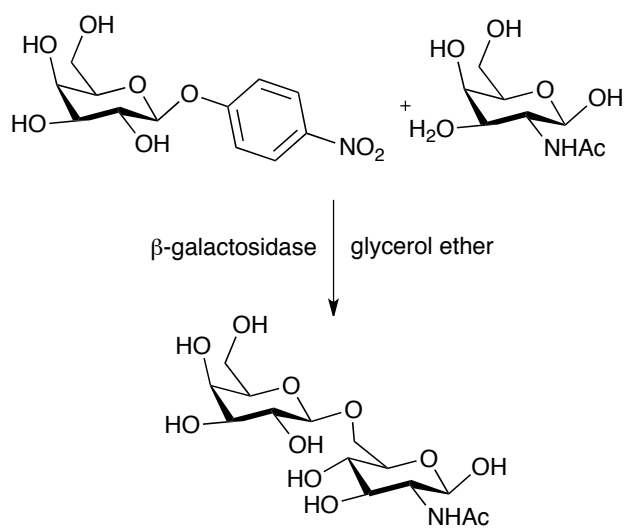

Scheme 47 General scheme of transglycosylation reaction catalyzed by $\beta$-galactosidase from $E$. coli in glycerol ethers

As previously mentioned, highly alkylated glycerol ethers are 5 useful as oxygenate additives for an internal combustion engine fuel. ${ }^{192}$ In this regard, glycerol dimethylethers and glycerol trimethylether can be used in processes for diesel or gasoline engines to reduce the emission of particulate matter, hydrocarbons, carbon monoxide and other contaminants. ${ }^{193,194}$

${ }_{10}$ The addition of these derivatives modifies the distillation curve, which could help to solve some problems from the point of view of engine operability and fuel design. ${ }^{195}$

Furthermore, some glycerol ethers have interest as amphiphilic solvents for cleaning and dry-cleaning, and their use have already 15 been protected under patent application. ${ }^{133}$ Other patents mention them as components in water based cutting fluids, helping to reduce the generation of frictional heat. ${ }^{196}$ Moreover, they have been studied as potential ingredients in heat transfer fluids, ${ }^{197}$ or as one of the five-component mixture of an organic 20 chlorohydrocarbon-free paint and varnish stripping and solvent cleaner. ${ }^{198}$ There are also some uses described as cryoprotective agents for freezing in aqueous solutions, as they modify the glassforming and stability properties. ${ }^{199}$

Two hyperbranched polyglycerols (HBPG) and one 25 oligoglycerol containing bisphenol $\mathrm{A}$ in the core of the molecule were synthesized from glycerol carbonate and applied as polyols in two-component polyurethane adhesive systems. It was shown that mechanical performance of the joints made in solid wood depended on the hydroxyl functionality of the polyglycerol as

30 well as on the type of the isocyanate used as a cross-linker. The shear strengths of the best-performing joints exceeded that of the substrate. Eventually, it was proved that HBPG might be convenient glycerol-derived raw materials for polyurethane adhesives. $^{200}$

\section{${ }_{35}$ Other solvents and intermediates}

There are two kinds of common organic solvents that can be produced from glycerol, namely the glycols 1,2-propanediol $(1,2-$ PDO, propylene glycol) and 1,3-propanediol (1,3-PDO), and butanol (Scheme 48).

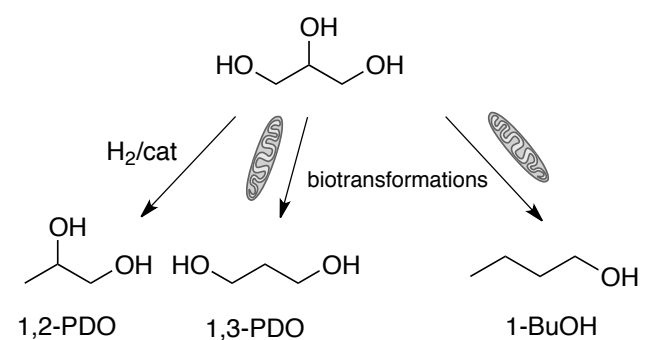

Scheme 48 Synthetic routes to glycols and butanol from glycerol

Propylene glycol is usually obtained through hydrogenolysis of glycerol, promoted by heterogeneous catalysts. For instance, The production of propylene glycol from glycerol in $\mathrm{H}_{2}$ atmosphere ${ }_{45}$ has been achieved using 5 wt $\% \mathrm{Ru} / \mathrm{SiO}_{2}$ catalyst. ${ }^{201}$ At the optimum reaction conditions glycerol conversion reaches the value of $c a .22 \%$ along with $60.5 \%$ selectivity.

In another recent work, the hydrogenolysis reaction was carried out in bioethanol solvent over small amounts of $\mathrm{Rh}$ -

${ }_{50}$ promoted $\mathrm{Cu} /$ solid-base catalysts prepared via layered double hydroxide precursors. ${ }^{202}$ The reaction proceeds more efficiently on $\mathrm{Rh}-\mathrm{Cu} /$ solid-base catalysts than in separated $\mathrm{Rh}$ and $\mathrm{Cu} /$ solidbase. The conversion of glycerol reached $91 \%$ with a selectivity to propylene glycol of $\mathrm{ca} .99 \%$ at $2.0 \mathrm{MPa} \mathrm{H}_{2}$ and $180{ }^{\circ} \mathrm{C}$. ${ }_{55}$ Furthermore, the catalyst was stable in five consecutive reaction cycles.

Catalytic hydrogenolysis, with high conversion and selectivity, is also promoted by supported palladium catalysts in isopropanol and dioxane at a low $\mathrm{H}_{2}$ pressure $(0.5 \mathrm{MPa}){ }^{203}$ The best ${ }_{60}$ performance, in terms of conversion and selectivity to propyleneglycol, was obtained with co-precipitated $\mathrm{Pd} / \mathrm{CoO}$ and $\mathrm{Pd} / \mathrm{Fe}_{2} \mathrm{O}_{3}$ catalysts in isopropanol and dioxane at $180^{\circ} \mathrm{C}$.

PtSn supported on $\mathrm{SiO}_{2}$ also catalyzes the hydrogenolysis of glycerol to obtain propylene glycol. ${ }^{204}$ The highest yield is ${ }_{65}$ obtained with the catalyst $\mathrm{PtSn}_{0.2}$ (propyleneglycol selectivity $=$ $59 \%$ and $83 \%$ under $\mathrm{N}_{2}$ and $\mathrm{H}_{2}$ pressure respectively). For higher tin contents, the decrease in the activity is related to the reduction of accessible platinum sites.

1,3-propanediol (1,3-PDO) is a chemical compound with 70 applications as monomer for the production of polyesters, polyethers and polyurethanes. Besides, it is a raw material for the production of biodegradable plastics, films, solvents, adhesives, detergents, cosmetics and medicines. Unlike propylene glycol, which is obtained through chemical catalytic methods, 1,3-PDO 75 is usually prepared from glycerol by fermentation and other biotechnological processes.

Recently published reviews ${ }^{205,206}$ gather different strategies that have been employed for the microbial production of 1,3PDO, which include the use of natural and/or genetically 80 engineered microorganisms. Thus, some strains of Citrobacter freundii, and Pantoea agglomerans were tested for their ability to produce 1,3-PDO from crude glycerol in shaken flask batch conditions and in packed bed biofilm reactors operating under continuous conditions. ${ }^{207}$ The best productivities were observed 85 when a hydraulic retention times of $2 \mathrm{~h}$ was applied. However, both strains were found to be good candidates for 1,3-PDO production in biofilm reactors, even though $P$. agglomerans displayed quite higher productivities $\left(3.6 \mathrm{~g} \mathrm{~L}^{-1} \mathrm{~h}^{-1}\right)$ than the other 
strain.

Crude glycerol causes significant inhibition of microbial growth and subsequently 1,3-PDO production is lower with crude as compared to pure glycerol. In a recent work a process was 5 developed for the treatment of crude glycerol using solvents before fermentation. ${ }^{208}$ Five different grades of crude glycerol (obtained from biodiesel preparation using jatropha, soybean, sunflower, rice bran and linseed oils) and four different non-polar solvents were examined yielding different grades of pretreated

10 glycerol. In some cases, 1,3-PDO productivities with treated crude glycerol were comparable to those obtained with the pure starting material.

Butanol, a four-carbon primary alcohol $\left(\mathrm{C}_{4} \mathrm{H}_{10} \mathrm{O}\right)$, is an important industrial chemical and, apart from its uses as solvent, 15 has a good potential to be used as a superior biofuel. Bio-based production of butanol from renewable feedstock is a promising and sustainable alternative to substitute petroleum-based fuels. Processes for butanol production from glycerol have been developed, mainly based on the use of strains of Clostridium 20 pasteurianum. Thus, a hyper-butanol producing strain of $C$. pasteurianum has been recently isolated by chemical mutagenesis. $^{209}$ The best mutant strain, C. pasteurianum MBEL_GLY2, was able to produce $10.8 \mathrm{~g} \mathrm{~L}^{-1}$ butanol from $80 \mathrm{~g}$ $\mathrm{L}^{-1}$ glycerol as compared to $7.6 \mathrm{~g} \mathrm{~L}^{-1}$ butanol produced by the ${ }_{25}$ parent strain. Next, the process parameters were optimized to maximize butanol production from glycerol. Under the optimized batch condition, the butanol concentration, yield, and productivity of $17.8 \mathrm{~g} \mathrm{~L}^{-1}, 0.30 \mathrm{~g} \mathrm{~g}^{-1}$, and $0.43 \mathrm{~g} \mathrm{~L}^{-1} \mathrm{~h}^{-1}$ could be achieved. Finally, continuous fermentation of $C$. pasteurianum 30 MBEL_GLY2 with cell recycling was carried out using glycerol as a major carbon source at several different dilution rates. The continuous fermentation was run for $710 \mathrm{~h}$ without strain degeneration. The acetone-butanol-ethanol productivity and the butanol productivity of 8.3 and $7.8 \mathrm{~g} \mathrm{~L}^{-1} \mathrm{~h}^{-1}$, respectively, could 35 be achieved at the dilution rate of $0.9 \mathrm{~h}^{-1} .^{209}$

Medium compositions favoring butanol and 1,3-PDO production from glycerol by $C$. pasteurianum DSM525 have been investigated using statistical experimental designs. ${ }^{210}$ Medium components affecting butanol and 1,3-PDO production were 40 screened using a fractional factorial experimental design. Optimal butanol $\left(0.98 \mathrm{~g} \mathrm{~L} \mathrm{~L}^{-1} \mathrm{~h}^{-1}\right)$ and 1,3-PDO $\left(1.19 \mathrm{~g}^{-1} \mathrm{~h}^{-1}\right)$ productivities were predicted by the corresponding quadratic model for each product and the models were validated experimentally under optimized conditions. The optimal medium 45 composition for butanol production was significantly different from that for 1,3-PDO, suggesting that product formation from glycerol by $C$. pasteurianum DSM525 can be controlled by changing medium compositions.

\section{Solvent substitution: the challenge}

${ }_{50}$ Although the number of papers covering the synthesis and applications of "green solvents" is increasingly growing, systematic studies about solvent substitution issues are still scarce, in spite of the importance of the topic. Citing the Jessops's statement: “... green solvent will only be chosen if one 55 exists with the desired properties." ${ }^{211}$ It becomes then clear that the efficient and systematic search for possible substitution applications requires the determination of the physico-chemical and toxicological properties of the new solvents, and their quantitative comparison with those of conventional organic 60 solvents they are supposed to replace.

\section{Common organic solvents hazards. How they compare with} glycerol-derived solvents?

Most organic solvents derived from petroleum are flammable and volatile, and their use and manipulation is often dangerous. ${ }_{65}$ Furthermore, many of them are poisonous when they are swallowed or inhaled in sufficient quantity, and long-term exposure at lower concentrations can cause brain damage, especially in the case of aromatic, aliphatic and chlorinated hydrocarbons.

70 Some insights about how glycerol-derived solvents compare with most common organic solvents can be gained by examining Table 9. Concerning flammability, one of the typical hazards of organic solvents, experimental values available for glycerolderived solvents are in general higher than those of common 75 organic solvents. Following the EPA and OSHA definitions, glycerol-derived solvents are classified as combustible liquids (flash point between 38 and $93{ }^{\circ} \mathrm{C}$ ), whereas most of common organic solvents are classified as flammable (flash point below 38 ${ }^{\circ} \mathrm{C}$ ). In fact, there is a clear relationship between boiling and flash 80 points. Using the experimental data of 24 common organic solvents and 5 glycerol-derived solvents a good linear relationship is found, as depicted in Figure 5, obeying the following equation:

$$
\begin{gathered}
\text { F.p. }\left({ }^{\circ} \mathrm{C}\right)=0.815 \cdot \text { B.p. }\left({ }^{\circ} \mathrm{C}\right)-66.2 \\
\mathrm{~N}=29, \mathrm{r}=0.980, \mathrm{~s}=11.4, F_{1,27}=656.2
\end{gathered}
$$

85 Thus, following this equation, it is easy to foresee that none of the glycerol-derived solvents shown in Table 9 (which are representative of all the families discussed in this review) fall within the flammable solvent category. The predicted flash points of the unknown cases lie between 79 and $154{ }^{\circ} \mathrm{C}$, and all the 90 boiling points of the different glycerol derivatives described are higher than that of 1,2,3-trimethoxypropane.

Similarly, the vapor pressures at room temperature of most glycerol-derived solvents are very low (usually below 1 Torr), whereas the situation in the case of common organic solvents is 95 the opposite. Therefore, those hazards related with vapor concentration, such as flammability danger, toxicity by inhalation, long term exposure, air pollution, etc. should be greatly reduced upon the use of glycerol-derived solvents.

The comparison of other solvent features, such as dielectric 100 constant, hydrophobicity or polarity, as expressed by the Reichardt's parameter $E_{T}^{N},{ }^{212}$ indicates that glycerol-derived solvents cover a wide range of these properties, so they can be envisaged as potential substitutes of many of the common organic solvents gathered in Table 9 . 


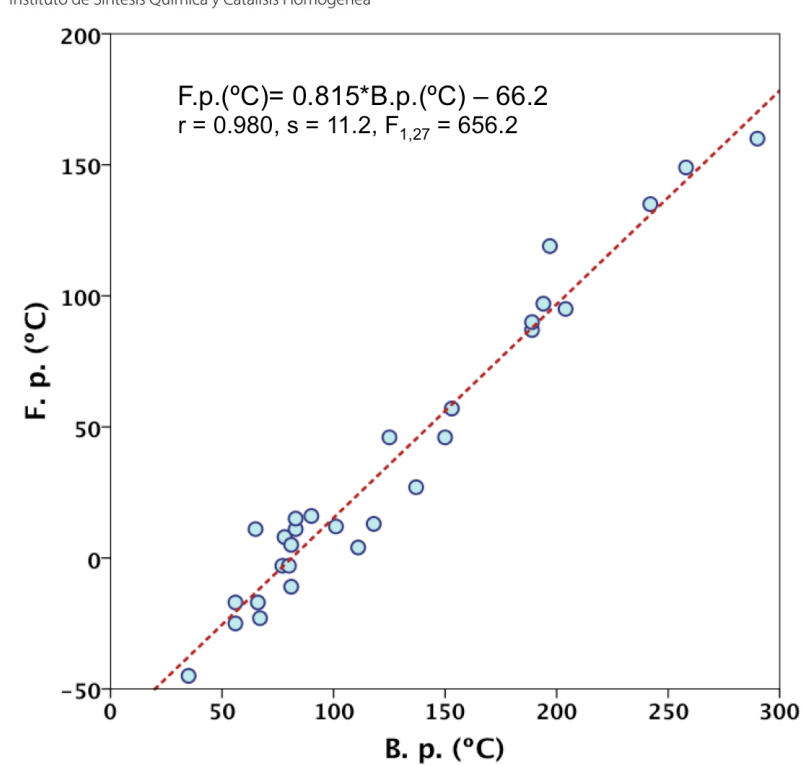

Fig. 5 Linear relationship found between the boiling and flash points of 29 solvents, including both petroleum and glycerol-derived.

Toxicity is undoubtedly one of the key aspects to take into 5 account when considering solvent hazard issues. Unfortunately, there is an important lack of systematic toxicity studies involving glycerol derivatives. One of the most widely available tests of toxicity for mammals is the oral $\mathrm{LD}_{50}$ for rats. Although this toxicity index is far for being truly representative (many of 10 organic solvents having a well-known toxicity for humans display low oral toxicity in rats), we have gathered some comparative values in Table 9. As can be seen, most of glycerol derivatives display a toxicity similar to that observed for common organic solvents. In some cases, the toxicity is remarkably low, as for 15 glycerol and some glycerol monoalkyl ethers.

Table 9. Some relevant physico-chemical properties of common organic solvents and glycerol derivatives. ${ }^{\mathrm{a}, \mathrm{b}}$

\begin{tabular}{|c|c|c|c|c|c|c|c|c|}
\hline Solvent & $\begin{array}{l}\text { B.p. } \\
\left({ }^{\circ} \mathrm{C}\right)\end{array}$ & $\begin{array}{c}\text { Flash p. } \\
\left({ }^{\circ} \mathrm{C}\right)\end{array}$ & $\begin{array}{l}\text { Vap. P. } \\
\text { (Torr) }\end{array}$ & $\log P$ & $\varepsilon$ & $\begin{array}{c}\mu \\
\text { (D) }\end{array}$ & $E_{T}^{N}$ & $\underset{\left(\mathrm{g} \mathrm{kg}^{-1}\right)^{\mathrm{c}}}{\mathbf{L}_{50}}$ \\
\hline Methanol & 64.7 & 11 & 96 & -0.77 & 32.7 & 9.6 & 0.762 & $6-13$ \\
\hline Ethanol & 78 & 8 & 44 & -0.31 & 24.6 & 5.5 & 0.654 & $7-15$ \\
\hline tert-Butanol & 83 & 11 & 31 & 0.51 & 12.5 & 5.5 & 0.389 & 3.5 \\
\hline Ehylene glycol & 196-198 & 119 & 0.1 & -1.93 & 37.7 & 7.7 & 0.790 & 4.7 \\
\hline 2-Methoxyethanol & $124-125$ & 46 & 6 & -0.77 & 16.9 & 6.8 & 0.657 & \\
\hline Toluene & 111 & 4 & 21 & 2.73 & 2.4 & 1.0 & 0.099 & $5.5-7.4$ \\
\hline$p$-Xylene & $137-138$ & 27 & 9 & 3.15 & 2.3 & 0.0 & 0.074 & $<8.6$ \\
\hline Acetonitrile & $80-82$ & 5 & 73 & -0.34 & 35.9 & 13.0 & 0.460 & 2.5 \\
\hline Dimethylformamide & 153 & 57 & 3 & -0.74 & 36.7 & 12.7 & 0.386 & $<2.8$ \\
\hline Dimethylsulfoxide & 189 & 87 & $<1$ & -1.35 & 46.5 & 13.5 & 0.444 & $<8$ \\
\hline$N$-Methyl pyrrolidone & 204 & 95 & 0.2 & -0.40 & 32.2 & 13.6 & 0.355 & 3.9 \\
\hline Ethyl acetate & 77 & -3 & 73 & 0.73 & 6.0 & 5.9 & 0.228 & 5.6 \\
\hline Dimethyl carbonate & 90 & 16 & 56 & 0.15 & 2.8 & 3.0 & 0.232 & 13 \\
\hline Propylene carbonate & 242 & 135 & 0.2 & -0.41 & 66.6 & & 0.472 & \\
\hline Diethyl ether & 35 & -45 & 440 & 0.77 & 4.2 & 3.8 & 0.117 & $1.2-1.7$ \\
\hline Methyl tert-butyl ether & $55-56$ & -25 & 205 & 1.15 & 4.5 & 4.1 & 0.124 & $<4$ \\
\hline Tetrahydrofuran & 66 & -17 & 132 & 0.46 & 7.6 & 5.8 & 0.207 & $<1.7$ \\
\hline 2-MeTHF & $80-82$ & -11 & 97 & 0.82 & & & 0.179 & \\
\hline 1,4-Dioxane & $100-102$ & 12 & 29 & -0.42 & 2.2 & 1.5 & 0.164 & $5.3-7.1$ \\
\hline Dichloromethane & $39-40$ & & 350 & 1.25 & 8.9 & 3.8 & 0.309 & $<2.1$ \\
\hline Chloroform & 61 & & 160 & 1.97 & 4.9 & 3.8 & 0.259 & $0.5-1.4$ \\
\hline 1,2-Dichloroethane & 83 & 15 & 87 & 3.60 & 10.4 & 6.1 & 0.327 & $<0.7$ \\
\hline n-Hexane & $65-70$ & -23 & 124 & 3.80 & 1.9 & 0.0 & 0.009 & $<16$ \\
\hline Acetone & 56 & -17 & 180 & -0.24 & 20.6 & 9.0 & 0.355 & \\
\hline 2-Butanone & 80 & -3 & 78 & 0.37 & 18.1 & 9.2 & 0.327 & $2.5-3$ \\
\hline Methyl isobutyl ketone & $117-118$ & 13 & 16 & 1.25 & 13.1 & 9.0 & 0.269 & 2.1 \\
\hline Glycerol & 290 & 160 & 0.0 & -2.32 & 44.4 & 2.7 & 0.812 & 12.6 \\
\hline Triacetin & $257-259$ & 149 & 0.0 & 0.40 & 7.1 & 2.5 & 0.299 & 3 \\
\hline Glycerol carbonate & & $>190$ & 0.1 & -1.77 & 110 & 5.1 & & \\
\hline Solketal & 188-190 & 90 & 0.2 & 0.06 & & & & \\
\hline Glycerol formal $^{\mathrm{d}}$ & 193 & 76 & 0.1 & -0.97 & $110^{\mathrm{e}}$ & $2.1^{\mathrm{f}}$ & & \\
\hline $111^{\mathrm{g}}$ & 150 & 46 & 6.8 & -0.22 & 6.8 & 2.2 & & $>2$ \\
\hline $114 \mathrm{t}^{\mathrm{h}}$ & 180 & & 0.8 & 0.75 & & & 0.210 & \\
\hline $404^{i}$ & 248 & & 0.0 & 2.07 & 5.6 & 2.4 & 0.450 & 3.7 \\
\hline $3 \mathrm{i} 03 \mathrm{i}^{\mathrm{j}}$ & 202 & & 0.5 & 0.86 & & & & 1.5 \\
\hline $3 \mathrm{~F} 03 \mathrm{~F}^{\mathrm{k}}$ & 197 & & 0.4 & 1.42 & 14.6 & 4.1 & 0.700 & \\
\hline $3 \mathrm{~F} 13 \mathrm{~F}^{1}$ & 178 & & 0.4 & 1.83 & 13.7 & 4.2 & 0.550 & \\
\hline $444^{\mathrm{m}}$ & 270 & & $<0.1$ & 3.80 & 4.7 & 2.4 & 0.150 & \\
\hline
\end{tabular}




$\begin{array}{rccccc}200^{\mathrm{n}} & 221 & 18.6 & 3.4 & 0.690 & 9.4 \\ 101^{\mathrm{o}} & 170 & 13.0 & 2.9 & 0.610 & >3 \\ 4 \mathrm{t} 01^{\mathrm{p}} & 195 & 6.6 & 3.4 & 0.440 \\ 03 \mathrm{i} 0^{\mathrm{q}} & & & & & \\ 4 \mathrm{i} 04 \mathrm{i}^{\mathrm{r}} & & & & & \\ \end{array}$

${ }^{a}$ Italicized numbers correspond to estimated values. ${ }^{b}$ Values taken from refs. 183 and 212, and from Chemspider and Reaxys Databases. ${ }^{c}$ Oral in rat. ${ }^{d}$ Glycerol formal is a mixture of 4-hydroxymethyl-1,3-dioxolane and 5-hydroxy-1,3-dioxane. ${ }^{\mathrm{e}}$ Experimental value corresponding to 4-hydroxymethyl-1,3dioxolane. ${ }^{\mathrm{f}}$ Experimental value corresponding to 5-hydroxy-1,3-dioxane. ${ }^{\mathrm{g}}$ 1,2,3-trimethoxypropane. ${ }^{\mathrm{h}}$ 1,2-dimethoxy-3-tert-butoxypropane. ${ }^{\mathrm{i}}$ 1,3dibutoxypropan-2-ol. ${ }^{\mathrm{j}}$ 1,3-diisopropoxypropan-2-ol. ${ }^{\mathrm{k}}$ 1,3-bis(trifluoroethoxy)propan-2-ol. ${ }^{1}$ 1,3-bis(trifluoroethoxy)-2-methoxypropane. $\mathrm{m}$ 1,2,35 tributoxypropane. ${ }^{\mathrm{n}}$ 3-ethoxypropan-1,2-diol ${ }^{\mathrm{o}}$ 1,2-dimethoxypropan-2-ol ${ }^{\mathrm{p}}$ 1-tert-butoxy-3-methoxypropan-2-ol ${ }^{\mathrm{q}}$ 2-isopropoxypropan-1,3-diol ${ }^{\mathrm{r}}$ 1,3bis(isobuthoxy)propan-2-ol.

\section{Towards a systematic approach for solvent substitution}

Some interesting works have been recently published, covering 10 total or partially this issue. Probably, the most enlightening one is the perspective article "Searching for green solvents", published by Philip Jessop. ${ }^{211}$ Within the challenges proposed in this paper, the first one is entitled "populating the diagram", and its statement is "Ensure that green solvents are available as 15 replacement for non-green solvents of any kind." To define a solvent properties space, this author proposes the use of the wellknown Kamlet-Taft and Reichardt solvatochromic parameters, which cover the most relevant components of the so-called "solvent polarity". ${ }^{212}$ Using these parameters, property maps can 20 be drawn, where both conventional and green solvents are placed. Substitution candidates are then proposed on the basis of closeness in these maps. A problem that becomes immediately clear when examining these plots is that there are large areas where no green solvents alternatives exist. These areas comprise 25 high basicity/low polarity, high basicity/high polarity and low basicity/medium-to-high polarity solvents, which makes it difficult finding substitutive green solvents for HMPA, halogenated and aromatic solvents, respectively.

An extensive determination of solvatochromic parameters of 30 green solvents has been recently published by Jessop et al. ${ }^{213}$ This large compilation (83 molecular solvents, 18 switchable solvents and 187 ionic liquids) includes some glycerol derivatives, like glycerol itself, glycerol formal, triacetin and some glycerol ethers. Even with such small sample (7 solvents), 35 the versatility of glycerol-derived solvents becomes clear. For instance, the range of $E_{T}^{N}$ values is $0.30-0.82$ in a scale from 0 to 1. Compare with most of dialkylimidazolium ionic liquids (over 40 examples), whose $E_{T}^{N}$ values range from 0.55 to 0.70 .

A more extensive determination of $E_{T}^{N}$ values of glycerol40 derived solvents (46 instances), as well as other interesting physico-chemical properties, has been carried out by García et $a l{ }^{183}$ The range of $E_{T}^{N}$ values in this case is $0.15-0.71$ (0.82 if glycerol is included), which covers a broad range of solvent polarity, although not in a fully continuous way (Figure 6).

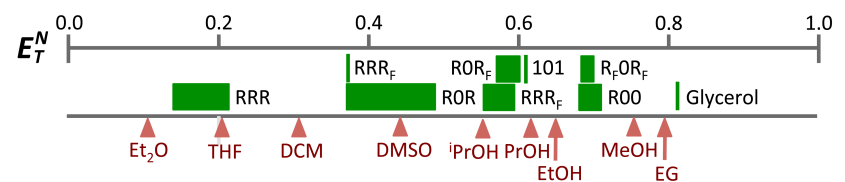

Fig. 6 Range of $E_{T}^{N}$ values covered by glycerol and glycerol alkyl ethers, including fluorinated alkyl chains. Some common organic solvents are also shown for comparison.

50

2D and 3D solvent properties maps have also been used to help locating the best targets for solvent substitution. Figure 7 displays an extensive comparison of solvents based on their $E_{T}^{N}$ and $\log \mathrm{P}$ (hydrophobicity) parameters. As can be seen, glycerol derivatives ${ }_{55}$ cover a broad zone of this map (note, however, that this situation could dramatically change if other properties are considered instead or in addition to). There is a subclass of the glycerol ethers that deserves particular comment, namely that bearing fluorinated alkyl chains. Some of these derivatives lie in a zone of 60 the map where no conventional organic solvents exist. This is due to the unusual combination of high polarity with high hydrophobicity, a combination that can only be found in some ionic liquids. This allows finding interesting applications of these solvents as reaction media for catalytic reactions, as already ${ }_{65}$ mentioned in the section of glycerol ethers.

The determination of solvatochromic parameters and other solvent properties can be a difficult task, above all if the synthesis of the glycerol derivatives is involved. An interesting possibility would be the prediction of such properties before accomplishing 70 the synthesis of the suitable substitution solvent. A recent work has been published dealing with the prediction of glycerol ethers properties using several QSPR (Quantitative Structure-Properties Relationships) approaches. ${ }^{214}$

Another recent work trying to systematize the classification of 75 green solvents is that published by Aubry and co-workers, ${ }^{215}$ who use a different approach. Instead of empirical solvent parameters, the theoretical COSMO-RS (COnductor-like Screening MOdel for Real Solvents) method is employed. A very large dataset of 153 common organic solvents and 138 green solvents was 80 considered included in the study. After parameterization of the solvents through their $\sigma$-potential distribution (61 values for each solvent) a clustering procedure was applied, in which the 138 green solvents were assigned to one of the 10 clusters determined with the 153 common solvents. Among the green solvents 85 considered, 22 glycerol derivatives were classified into three main groups: aprotic dipolar (e.g. triacetin, glycerol tributyl ether), amphiprotic (e.g. glycerol 1,3-dimethyl ether, glycerol 1butyl monoether, solketal), and polar protic (e.g. glycerol formal, glycerol carbonate, glycerol). The unusual behavior of fluorinated 90 alkyl ethers of glycerol was also highlighted in this analysis. Thus, the two examples included in the dataset (1,3bis(trifluoroethoxy)-2-propanol and 1,3-bis(heptafluorobutoxy)- 
2-propanol) can be classified either as asymmetric halogenated compounds or as amphiprotic.

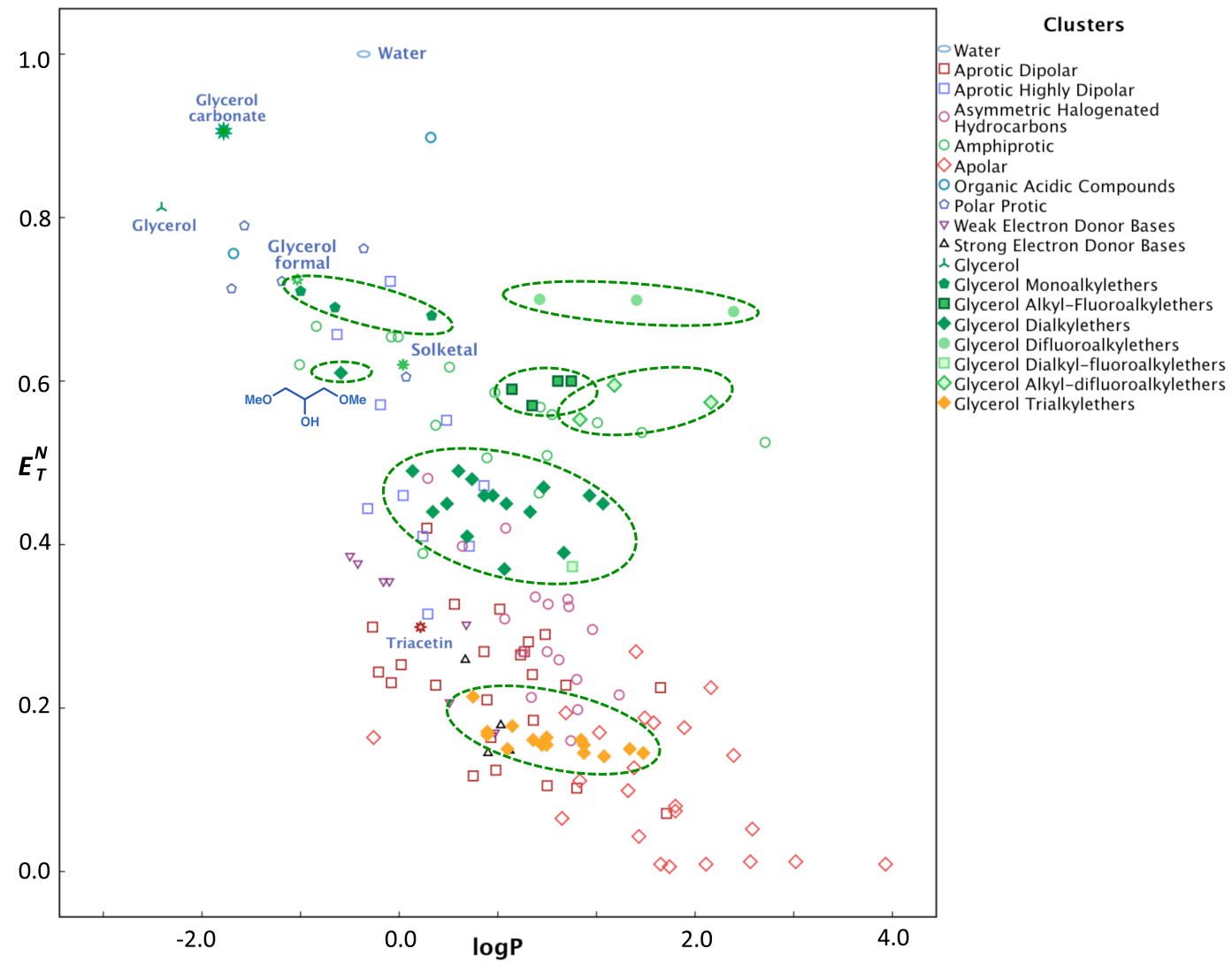

5 Fig. 7 Plot of $E_{T}^{N}$ vs. $\log$ P values of a series of common organic solvents (open symbols) and glycerol derivatives (filled symbols), classified according to the clusters defined in ref. 215 .

During the revision of this review, another work from Aubry's 10 group, dealing with the selection of greener solvent sets by means of a mathematical space-filling design, has appeared as an ASAP web article. ${ }^{216}$ In this paper, a database of 220 solvents is used to find a set of 40 solvents exhibiting satisfying environmental, health and safety (EHS) hazards profiles, with improved coverage 15 of Hensen solubility parameters. There are eight glycerol-derived solvents among them: glycerol, glycerol carbonate, glycerol formal, glycerol-2-monomethyl ether, glycerol-1,2-dimethyl ether, glycerol-1,3-dimethyl ether, glycerol-1,2,3-triethyl ether, and glycerol-1,2-dibutyl ether. This supports the idea that

20 glycerol derivatives, and particularly glycerol ethers, are good green candidates to be considered for solvent substitution.

\section{Conclusions}

Although glycerol derivatives do not seem to be the most popular candidates as the green solvents of the future, according to the ${ }_{25}$ Jessop's survey, ${ }^{211}$ they are receiving a growing interest from researchers and industries, as demonstrated by the increasing number of articles, reviews and patents devoted to them. This is in part due to the availability of huge amounts of glycerol at low prices, coming from biodiesel industry, but also to the chemical
30 versatility of the parent molecule, which allows a large molecular diversity upon derivatization.

The main threat to a widespread use of glycerol derivatives as solvents lies in the highly fluctuating prices, following not only changes in biodiesel prices, but also the industrial demand. For 35 instance, during year 2010, the price of refined glycerin in Asian market almost doubled (from $c a$. 500US\$/metric ton to $c a .900$ US\$/metric ton). Prices remain high in 2013 (well over 800 US\$/metric ton), because of the increasing production of glycerol-based epichlorohydrin by Chinese industries.

40 There are other issues to be addressed before new glycerolderived solvents can be massively used. The use of crude glycerin instead of refined glycerol is an interesting possibility, still scarcely explored in the literature. Admittedly, crude glycerol composition is detrimental for many applications. However, 45 simple pretreatments could improve the range of applicability of this raw material. Some recent encouraging examples in this direction are included in this review.

Another key point is the easy, inexpensive and green synthesis of the target glycerol derivatives in a large scale. To be ${ }_{50}$ competitive with petroleum-derived solvents, we should be able to fulfill the three above-mentioned conditions. It is clear that a big deal of work is still necessary in many cases.

Furthermore, systematic and reliable methods to find the best 
substitution solvent for a given application, in an easy and effective manner, must be available to all the potential users. Recent and encouraging advances in this sense have been published (some of them have been gathered in this review) but 5 more works on this topic will certainly be welcome.

Last, but not least, although the low toxicity and environmental impact of glycerol derivatives is often assumed, more toxicological and eco-toxicological studies are necessary, if these kinds of solvents are going to be used in larger amounts.

\section{${ }_{10}$ Acknowledgements}

Financial support from the Spanish MINECO (project CTQ201128124-C02-01, the European Social Fund (ESF) and the Gobierno de Aragón (Grupo Consolidado E11) is gratefully acknowledged.

\section{${ }_{15}$ Notes and references}

${ }^{a}$ Instituto de Síntesis Quimica y Catálisis Homogénea (ISOCH), Facultad de Ciencias, Universidad de Zaragoza-CSIC, calle Pedro Cerbuna 12, E50009 Zaragoza, Spain.Tel: +34 976762271; E-mail: jig@unizar.es.

201 S. Claude, Lipid Fett, 1999, 101, 101-104.

2. M. Pagliaro, R. Ciriminna, H. Kimura, M. Rossi, and C. Della Pina, Angew. Chem. Int. Ed., 2007, 46, 4434-4440.

3. C.-H. (Clayton) Zhou, J. N. Beltramini, Y.-X. Fan, and G. Q. (Max) Lu, Chem. Soc. Rev., 2008, 37, 527-549.

25 4. B. Katryniok, H. Kimura, E. Skrzyńska, J.-S. Girardon, P. Fongarland, M. Capron, R. Ducoulombier, N. Mimura, S. Paul, and F. Dumeignil, Green Chem., 2011, 13, 1960-1979.

5. J. Barrault and F. Jerome, Eur. J. Lipid Sci. Technol., 2008, 110, $825-830$.

30 6. F. Jérôme, Y. Pouilloux, and J. Barrault, ChemSusChem, 2008, 1, 586-613.

7. A. Brandner, K. Lehnert, A. Bienholz, M. Lucas, and P. Claus, Top. Catal., 2009, 52, 278-287.

8. M. Pagliaro, R. Ciriminna, H. Kimura, M. Rossi, and C. Della

35 Pina, Eur. J. Lipid Sci. Technol., 2009, 111, 788-799.

9. B. Katryniok, S. Paul, V. Bellière-Baca, P. Rey, and F. Dumeignil, Green Chem., 2010, 12, 2079-2098.

10. M. Simões, S. Baranton, and C. Coutanceau, ChemSusChem, 2012, 5, 2106-2124

40 11. Z. Y. Zakaria, N. A. S. Amin, and J. Linnekoski, Biomass Bioenergy, 2013, 55, 370-385.

12. Y. Gu and F. Jérôme, Green Chem., 2010, 12, 1127-1138.

13. A. Díaz-Álvarez and V. Cadierno, Appl. Sci., 2013, 3, 55-69.

14. A. E. Díaz-Álvarez, J. Francos, B. Lastra-Barreira, P. Crochet, and

45 V. Cadierno, Chem. Commun., 2011, 47, 6208-6227.

15. A. Wolfson, A. Snezhko, T. Meyouhas, and D. Tavor, Green Chem. Lett. Rev., 2012, 5, 7-12.

16. A. Ying, Q. Zhang, H. Li, G. Shen, W. Gong, and M. He, Res. Chem. Intermed., 2013, 39, 517-525.

50 17. A. Kumar, M. Kumar, M. K. Gupta, and L. P. Gupta, Rsc Adv., 2012, 2, 8277-8280.

18. F. He, P. Li, Y. Gu, and G. Li, Green Chem., 2009, 11, 1767-1773.

19. J.-N. Tan, M. Li, and Y. Gu, Green Chem., 2010, 12, 908-914.

20. G. Perin, L. G. Mello, C. S. Radatz, L. Savegnago, D. Alves, R. G

55 Jacob, and E. J. Lenardão, Tetrahedron Lett., 2010, 51, 4354-4356.

21. D. M. L. Cabrera, F. M. Libero, D. Alves, G. Perin, E. J. Lenardao, and R. G. Jacob, Green Chem. Lett. Rev., 2012, 5, 329-336.

22. A. Wolfson, H. Kimchi, and D. Tavor, Asian J. Chem., 2011, 23, $1227-1229$

60 23. H. R. Safaei, M. Shekouhy, S. Rahmanpur, and A. Shirinfeshan, Green Chem., 2012, 14, 1696-1704.

24. K. U. Sadek, R. A. Mekheimer, A. M. A. Hameed, F. Elnahas, and M. H. Elnagdi, Molecules, 2012, 17, 6011-6019.

25. C. S. Radatz, R. B. Silva, G. Perin, E. J. Lenardão, R. G. Jacob, 65 and D. Alves, Tetrahedron Lett., 2011, 52, 4132-4136.
26. H. M. Bachhav, S. B. Bhagat, and V. N. Telvekar, Tetrahedron Lett., 2011, 52, 5697-5701.

27. T. G. Deligeorgiev, S. S. Kaloyanova, N. Y. Lesev, and J. J. Vaquero, Monatshefte Für Chem. - Chem. Mon., 2011, 142, 895899.

28. J. E. R. Nascimento, A. M. Barcellos, M. Sachini, G. Perin, E. J. Lenardão, D. Alves, R. G. Jacob, and F. Missau, Tetrahedron Lett., 2011, 52, 2571-2574.

29. M. Delample, N. Villandier, J.-P. Douliez, S. Camy, J.-S. Condoret, Y. Pouilloux, J. Barrault, and F. Jérôme, Green Chem., 2010, 12, 804-808.

30. N. Bakhrou, F. Lamaty, J. Martinez, and E. Colacino, Tetrahedron Lett., 2010, 51, 3935-3937.

31. L. C. Gonçalves, G. F. Fiss, G. Perin, D. Alves, R. G. Jacob, and E. J. Lenardão, Tetrahedron Lett., 2010, 51, 6772-6775.

32. V. G. Ricordi, C. S. Freitas, G. Perin, E. J. Lenardao, R. G. Jacob, L. Savegnago, and D. Alves, Green Chem., 2012, 14, 1030-1034.

33. P. K. Khatri and S. L. Jain, Tetrahedron Lett., 2013, 54, 27402743.

85 34. N. Seyedi, Transit. Met. Chem., 2013, 38, 93-103.

35. C. Mukhopadhyay and A. Datta, Synth. Commun., 2013, 43, 438449.

36. Z.-J. Quan, R.-G. Ren, Y.-X. Da, Z. Zhang, and X.-C. Wang, Synth. Commun., 2011, 41, 3106-3116.

90 37. M. Benoit, Y. Brissonnet, E. Guelou, K. D. O. Vigier, J. Barrault, and F. Jerome, ChemSusChem, 2010, 3, 1304-1309.

38. G. Cravotto, L. Orio, E. C. Gaudino, K. Martina, D. Tavor, and A. Wolfson, ChemSusChem, 2011, 4, 1130-1134.

39. D. Alves, M. Sachini, R. G. Jacob, E. J. Lenardão, M. E. Contreira, L. Savegnago, and G. Perin, Tetrahedron Lett., 2011, 52, 133-135.

40. M. J. Hernaiz, A. R. Alcantara, J. I. Garcia, and J. V. Sinisterra, Chem.- Eur. J., 2010, 16, 9422-9437.

41. A. Wolfson, C. Dlugy, D. Tavor, J. Blumenfeld, and Y. Shotland, Tetrahedron Asymmetry, 2006, 17, 2043-2045.

100 42. L. H. Andrade, L. Piovan, and M. D. Pasquini, Tetrahedron Asymmetry, 2009, 20, 1521-1525.

43. A. E. Díaz-Álvarez, P. Crochet, and V. Cadierno, Catal. Commun., 2011, 13, 91-96.

44. A. Azua, J. A. Mata, E. Peris, F. Lamaty, J. Martinez, and E. Colacino, Organometallics, 2012, 31, 3911-3919.

45. A. Azua, J. A. Mata, and E. Peris, Organometallics, 2011, 30, 5532-5536.

46. N. García, P. García-García, M. A. Fernández-Rodríguez, D. García, M. R. Pedrosa, F. J. Arnáiz, and R. Sanz, Green Chem., 2013, 15, 999-1005.

47. J. Kou and R. S. Varma, Chem. Commun., 2013, 49, 692-694.

48. R. Genç, G. Clergeaud, M. Ortiz, and C. K. O'Sullivan, Langmuir, 2011, 27, 10894-10900.

49. A. P. Abbott, R. C. Harris, K. S. Ryder, C. D'Agostino, L. F. 115 Gladden, and M. D. Mantle, Green Chem., 2011, 13, 82-90.

50. Q. Zhang, K. D. O. Vigier, S. Royer, and F. Jérôme, Chem. Soc. Rev., 2012, 41, 7108-7146.

51. H. Zhao and G. A. Baker, J. Chem. Technol. Biotechnol., 2013, 88, $3-12$.

120 52. K. R. Siongco, R. B. Leron, and M.-H. Li, J. Chem. Thermodyn., 2013, 65, 65-72.

53. R. B. Leron and M.-H. Li, J. Chem. Thermodyn., 2013, 57, 131136.

54. D. Yang, M. Hou, H. Ning, J. Zhang, J. Ma, G. Yang, and B. Han, Green Chem., 2013, 15, 2261-2265.

55. C. Li, D. Li, S. Zou, Z. Li, J. Yin, A. Wang, Y. Cui, Z. Yao, and Q. Zhao, Green Chem., 2013, 15, 2793-2799.

56. K. Shahbaz, F. S. Mjalli, M. A. Hashim, and I. M. AlNashef, Sep. Purif. Technol., 2011, 81, 216-222.

13057 H. Zhao, G. A. Baker, and S. Holmes, J. Mol. Catal. B-Enzym., 2011, 72, 163-167.

58. E. Durand, J. Lecomte, and P. Villeneuve, Eur. J. Lipid Sci. Technol., 2013, 115, 379-385.

59. M. Perez-Sanchez, M. Sandoval, M. Hernaiz, and P. María, Curr. Org. Chem., 2013, 17, 1188-1199.

60. H. R. Lobo, B. S. Singh, and G. S. Shankarling, Green Chem. Lett. Rev., 2012, 5, 487-533.

61. S. Handy and K. Lavender, Tetrahedron Lett., 2013, 54, 4377- 
4379

62. C. P. Papaneophytou, A. K. Mettou, V. Rinotas, E. Douni, and G. A. Kontopidis, ACS Med. Chem. Lett., 2013, 4, 137-141.

63. P. Lameiras, L. Boudesocque, Z. Mouloungui, J.-H. Renault, J.-M Wieruszeski, G. Lippens, and J.-M. Nuzillard, J. Magn. Reson., 2011, 212, 161-168.

64. Y. Shiraishi, T. Inoue, S. Sumiya, and T. Hirai, J. Phys. Chem. A, 2011, 115, 9083-9090.

65. G. Galgali, E. Schlangen, and S. van der Zwaag, Mater. Res. Bull., 2011, 46, 2445-2449.

66. Y. Jin, X. Ruan, X. Cheng, and Q. Lü, Bioresour. Technol., 2011 , 102, 3581-3583.

67. J. Xu, J. Jiang, W. Dai, and Y. Xu, Process Saf. Environ. Prot., 2012, 90, 333-338.

15 68. A. Behr, J. Eilting, K. Irawadi, J. Leschinski, and F. Lindner, Green Chem., 2008, 10, 13-30.

69. A. Corma, S. Iborra, and A. Velty, Chem. Rev., 2007, 107, 24112502.

70. Y. Zheng, X. Chen, and Y. Shen, Chem. Rev., 2008, 108

20 71. L. Zhou, E. Al-Zaini, and A. A. Adesina, Fuel, 2013, 103, 617 625

72. V. L. C. Gonçalves, B. P. Pinto, J. C. Silva, and C. J. A. Mota, Catal. Today, 2008, 133-135, 673-677.

73. J. A. Melero, R. van Grieken, G. Morales, and M. Paniagua, Energy Fuels, 2007, 21, 1782-1791.

74. S. Zhu, Y. Zhu, X. Gao, T. Mo, Y. Zhu, and Y. Li, Bioresour. Technol., 2013, 130, 45-51.

75. R. Luque, V. Budarin, J. H. Clark, and D. J. Macquarrie, Appl. Catal. B Environ., 2008, 82, 157-162.

30 76. M. S. Khayoon and B. H. Hameed, Bioresour. Technol., 2011, 102, 9229-9235

77. J. A. Sánchez, D. L. Hernández, J. A. Moreno, F. Mondragón, and J. J. Fernández, Appl. Catal. Gen., 2011, 405, 55-60.

78. M. L. Testa, V. La Parola, L. F. Liotta, and A. M. Venezia, J. Mol. Catal. Chem., 2013, 367, 69-76.

79. N. Bremus, G. Dieckelmann, L. Jeromin, W. Rupilius, and H. Schuett, Ger. Pat., 1981/DE3004660 A1.

80. Z. Yao, Z. Yin, P. Sun, X. Pang, W. Yuan, and Y. Qin, CN. Pat. 2012/102675095 A.

40 81. X. Liao, Y. Zhu, S.-G. Wang, and Y. Li, Fuel Process. Technol., 2009, 90, 988-993.

82. X. Li, J. Li, L. Huang, Y. Chen, and Y. Chen, CN. Pat., 2013 $102850215 \mathrm{~A}$

83. E. M. Usai, E. Gualdi, V. Solinas, and E. Battistel, Bioresour Technol., 2010, 101, 7707-7712.

84. G. Morales, M. Paniagua, J. A. Melero, G. Vicente, and C. Ochoa, Ind. Eng. Chem. Res., 2011, 50, 5898-5906.

85. P. Barbano and J. W. Sherbon, J. Am. Oil Chem. Soc., 1978, 55, 478-481.

50 86. R. J. Craven and R. W. Lencki, J. Am. Oil Chem. Soc., 2011, 88, $1125-1134$.

87. F. Cantini, WO Pat., 2010/106488 A2

88. C. Xiao, Z. Zhang, J. Zhang, Y. Lu, and L. Zhang, J. Appl. Polym. Sci., 2003, 89, 3500-3505.

55 89. W. F. Gary, Fr. Pat., 1977/2334303 A2.

90. L. J. Gauckler, T. Graule, and F. Baader, Mater. Chem. Phys., 1999, 61, 78-102.

91. P. Haas, Chem. Eng. Prog., 1989, 85, 44-52.

92. A. Gokhale, S. Padmanabhan, and C. Roberge, WO. Pat., 2012/027279 A1.

93. E. Holm and I. Schade, Aktuelle Ernährungsmedizin, 2008, 33, 225-230.

94. J.-T. Lo, B.-H. Chen, T.-M. Lee, J. Han, and J.-L. Li, J. Pharm. Sci., 2010, 99, 2320-2332.

65 95. G. S. Khang, J. C. Yang, J. T. Ko, J. S. Park, M. S. Kim, J. M. Rhee, and H. B. Lee, Key Eng. Mater., 2007, 342-343, 541-544.

96. S. N. Kang, S.-S. Hong, M.-K. Lee, and S.-J. Lim, Int. J. Pharm., 2012, 428, 76-81.

97. E. Wright, J. Huckle, and S. Ali, WO Pat., 2002/02098475 (A1).

70 98. A. Wolfson, A. Atyya, C. Dlugy, and D. Tavor, Bioprocess Biosyst. Eng., 2010, 33, 363-366.

99. A. Wolfson, D. Saidkarimov, C. Dlugy, and D. Tavor, Green Chem. Lett. Rev., 2009, 2, 107-110.
100. A. Wolfson, C. Dlugy, A. Karanet, and D. Tavor, Tetrahedron Lett., 2012, 53, 4565-4567.

101. S. Furusaki, S. Yamamoto, T. Hasegawa, and A. Kanbara, JP Pat., 2006/109784 (A)

102. M. O. Sonnati, S. Amigoni, E. P. T. de Givenchy, T. Darmanin, O. Choulet, and F. Guittard, Green Chem., 2013, 15, 283-306.

80 103. M. H. Ab Rahim, Q. He, J. A. Lopez-Sanchez, C. Hammond, N. Dimitratos, M. Sankar, A. F. Carley, C. J. Kiely, D. W. Knight, and G. J. Hutchings, Catal. Sci. Technol., 2012, 2, 1914-1924.

104. S. Fujita, Y. Yamanishi, and M. Arai, J. Catal., 2013, 297, 137141

85 105. M. Du, Q. Li, W. Dong, T. Geng, and Y. Jiang, Res. Chem. Intermed., 2012, 38, 1069-1077.

106. F. S. H. Simanjuntak, V. T. Widyaya, C. S. Kim, B. S. Ahn, Y. J. Kim, and H. Lee, Chem. Eng. Sci., 2013, 94, 265-270.

107. T. W. Turney, A. Patti, W. Gates, U. Shaheen, and S. Kulasegaram, Green Chem., 2013.

108. M. Tudorache, A. Nae, S. Coman, and V. I. Parvulescu, RSC Adv. 2013, 3, 4052-4058.

109. G. Ou, B. He, X. Li, and J. Lei, Sci. World J., 2012.

110. M. Kargar, R. Hekmatshoar, M. Ghandi, and A. Mostashari, J. Am. Oil Chem. Soc., 2013, 90, 259-264.

111. J. Bensemhoun and S. Condon, Green Chem., 2012, 14, 2595 2599.

112. A. J. Showler and P. A. Darley, Chem. Rev., 1967, 67, 427-440.

113. M. S. Newman and M. Renoll, J. Am. Chem. Soc., 1945, 67, 16211621 .

114. P. Sudarsanam, B. Mallesham, A. N. Prasad, P. S. Reddy, and B. M. Reddy, Fuel Process. Technol., 2013, 106, 539-545.

115. C. Crotti, E. Farnetti, and N. Guidolin, Green Chem., 2010, 12, 2225-2231.

105 116. B. L. Wegenhart and M. M. Abu-Omar, Inorg. Chem., 2010, 49, 4741-4743.

117. K. Kaneda, T. Mitsudome, T. Matsuno, S. Sueoka, T. Mizugaki, and K. Jitsukawa, Heterocycles, 2012, 84, 371.

118. J. Deutsch, A. Martin, and H. Lieske, J. Catal., 2007, 245, 428435

119. C. X. A. da Silva, V. L. C. Gonçalves, and C. J. A. Mota, Green Chem., 2009, 11, 38-41.

120. V. R. Ruiz, A. Velty, L. L. Santos, A. Leyva-Pérez, M. J. Sabater, S. Iborra, and A. Corma, J. Catal., 2010, 271, 351-357.

115 121. G. Vicente, J. A. Melero, G. Morales, M. Paniagua, and E. Martín, Green Chem., 2010, 12, 899-907.

122. C.-N. Fan, C.-H. Xu, C.-Q. Liu, Z.-Y. Huang, J.-Y. Liu, and Z.-X. Ye, React. Kinet. Mech. Catal., 2012, 107, 189-202.

123. L. Li, T. I. Korányi, B. F. Sels, and P. P. Pescarmona, Green Chem., 2012, 14, 1611-1619.

124. M. De Torres, G. Jimenez-Oses, J. A. Mayoral, E. Pires, and M. de los Santos, Fuel, 2012, 94, 614-616.

125. L. Roldan, R. Mallada, J. M. Fraile, J. A. Mayoral, and M. Menendez, Asia-Pac. J. Chem. Eng., 2009, 4, 279-284.

125 126. C. Piantadosi, C. E. Anderson, E. A. Brecht, and C. L. Yarbro, J. Am. Chem. Soc., 1958, 80, 6613-6617.

127. V. B. Vol'eva, I. S. Belostotskaya, A. V. Malkova, N. L. Komissarova, L. N. Kurkovskaya, S. V. Usachev, and G. G. Makarov, Russ. J. Org. Chem., 2012, 48, 638-641.

130 128. H. Garcia, J. I. Garcia, J. M. Fraile, and J. A. Mayoral, Chim. Oggi/Chemistry Today, 2008, 26, 10-12.

129. M. Perez-Sanchez, M. Sandoval, and M. J. Hernaiz, Tetrahedron, 2012, 68, 2141-2145.

130. H. Goto, A. Gotoh, K. Nagai, Y. Yokohama, and H. Fujii, WO. Pat., 2012/124790 A1.

131. J. E. Kim, S. Y. Chang, K. on Cha, S. K. Son, and J. J. Choi, KR Pat., 2012/0136699 A.

132. W. Lourenco, WO. Pat., 2012/143769 A1.

133. J. Y. Kim, S. K. Son, S. Y. Chang, J. J. Choi, and H. S. Kim, KR Pat., 2013/0021731 A.

134. M. Erman, Perfum. Flavorist, 2007, 32, 20-22.

135. A. Laurent, F. Mottu, R. Chapot, J. Q. Zhang, O. Jordan, D. A. Rüfenacht, E. Doelker, and J.-J. Merland, PDA J. Pharm. Sci. Technol., 2007, 61, 64-74.

145 136. J. A. E. Määttä, Y. Eisenberg-Domovich, H. R. Nordlund, R 
Hayouka, M. S. Kulomaa, O. Livnah, and V. P. Hytönen, Biotechnol. Bioeng., 2011, 108, 481-490.

137. F. Mottu, A. Laurent, D. A. Rüfenacht, and E. Doelker, PDA J. Pharm. Sci. Technol., 2000, 54, 456-469.

5 138. F. A. Alawi, W. F. Leech, and K. Nanjan, WO Pat., 2012/099479 A1

139. K. S. Pasloske, K. Lau, S. J. Richardson, and A. E. Willis, WO. Pat., 2013/078500 A1.

140. A. R. Kamuhabwa, K. R. Geboes, and P. A. De Witte, J. Pharm. 10 Pharmacol., 2000, 52, 487-494.

141. R. L. Dunn, US Pat., 2009/181068 A1.

142. M. Sun, L. Si, X. Zhai, Z. Fan, Y. Ma, R. Zhang, and X. Yang, Drug Dev. Ind. Pharm., 2011, 37, 986-994.

143. J.-J. Gasse, G. Duchamp, and M. Cantero, EP Pat., 2010/2266400 A1.

144. A. Pirotte, WO Pat., 2013/011108 A1.

145. S. Sabnis, J. Zupan, and M. Gliddon, Vet. Parasitol., 2007, 150, 196-202.

146. M. D. Soll, J. J. K. Rosentel, J. Pate, N. Shub, M. MotwaniTejwani, and C. Belansky, 2013.

147. L. P. Ozorio, R. Pianzolli, M. B. S. Mota, and C. J. A. Mota, $J$ Braz. Chem. Soc., 2012, 23, 931-937.

148. J. Kabatc, Polym. Bull., 2012, 68, 667-679.

149. S. Shi, H. Gao, G. Wu, and J. Nie, Polymer, 2007, 48, 2860-2865.

25 150. C. Estevez, F. Bayarri, B. Castells, and B. Echeverria, WO Pat., 2008/080601 A2.

151. H. Donner, F. Bergmann, B. Buchberger, and N. Lassonczyk, WO Pat., 2008/071385 A2.

152. J. X. H. Zhou, WO Pat., 2007/081906 A2.

30 153. J.-S. Chang, Y.-D. Lee, L. C.-S. Chou, T.-R. Ling, and T.-C. Chou, Ind. Eng. Chem. Res., 2012, 51, 655-661.

154. M. Lemaire, W. Dayoub, M. Sutter, and Y. Raoul, FR Pat., 2013/2981067 A1.

155. J. F. Izquierdo, M. Montiel, I. Pales, P. R. Outon, M. Galan, L. Jutglar, M. Villarrubia, M. Izquierdo, M. P. Hermo, and X. Ariza, Renew. Sustain. Energy Rev., 2012, 16, 6717-6724.

156. Y. Cesteros, M. D. González, P. Salagre, E. Taboada, and J. Llorca, Green Chem., 2013.

157. S. Bigot, H. Bricout, I. Suisse, A. Mortreux, and Y. Castanet, Ind. Eng. Chem. Res., 2011, 50, 9870-9875.

158. M. Sutter, W. Dayoub, E. Métay, Y. Raoul, and M. Lemaire, Green Chem., 2013, 15, 786-797.

159. M. Sutter, E. Metay, Y. Raoul, and M. Lemaire, Green Chem., $2013, \mathbf{1 5}, 347$.

45 160. M. Sutter, W. Dayoub, E. Métay, Y. Raoul, and M. Lemaire, ChemSusChem, 2012, 5, 2397-2409.

161. M. Ayoub, M. S. Khayoon, and A. Z. Abdullah, Bioresour Technol., 2012, 112, 308-312.

162. M. Ayoub and A. Z. Abdullah, Catal. Commun., 2013, 34, 22-25.

50 163. J.-S. Chang and D.-H. Chen, J. Taiwan Inst. Chem. Eng., 2011, 42, 760-767.

164. M. Pilar Pico, A. Romero, S. Rodriguez, and A. Santos, Ind. Eng. Chem. Res., 2012, 51, 9500-9509.

165. E. Vlad, C. S. Bildea, and G. Bozga, ScientificWorldJournal, 2012, 2012.

166. P. Gaudin, R. Jacquot, P. Marion, Y. Pouilloux, and F. Jérôme, Catal. Sci. Technol., 2011, 1, 616-620.

167. A. M. Truscello, C. Gambarotti, M. Lauria, S. Auricchio, G. Leonardi, S. U. Shisodia, and A. Citterio, Green Chem., 2013, 15, 625-628.

168. G. D. Yadav, P. A. Chandan, and N. Gopalaswami, Clean Technol. Environ. Policy, 2012, 14, 85-95.

169. J.-W. Yoo and Z. Mouloungui, in Studies in Surface Science and Catalysis, ed. R. R. Sang-Eon Park, Elsevier, 2003, vol. Volume 146 , pp. $757-760$.

170. S. Claude, Z. Mouloungui, J.-W. Yoo, and A. Gaset, US Pat., 2000/6025504 A.

171. J. S. Choi, F. S. H. Simanjuntaka, J. Y. Oh, K. I. Lee, S. D. Lee, M. Cheong, H. S. Kim, and H. Lee, J. Catal., 2013, 297, 248-255.

70 172. C. L. Bolivar-Diaz, V. Calvino-Casilda, F. Rubio-Marcos, J. F. Fernandez, and M. A. Banares, Appl. Catal. B-Environ., 2013, 129, 575-579.

173. T. Aoki, T. Ohe, and H. Ishikami, EP. Pat., 2000/1059278 A2.
174. P. Gilbeau, WO Pat., 2006/106154 A1.

75 175. P. Gilbeau, WO Pat., 2006/100311 A2.

176. D. Siano, E. Santacesaria, V. Fiandra, R. Tesser, N. Di, S. Di, and M. Nastasi, WO. Pat., 2006/111810 A2.

177. G. H. Posner and D. Z. Rogers, J. Am. Chem. Soc., 1977, 99, 82088214.

80 178. P. Salehi, M. M. Khodaei, M. A. Zolfigol, and A. Keyvan, Synth. Commun., 2003, 33, 3041-3048.

179. J. Otera, Y. Niibo, N. Tatsumi, and H. Nozaki, J. Org. Chem., 1988, 53, 275-278.

180. B. Tamami, N. Iranpoor, and M. A. K. Zarchi, Polymer, 1993, 34, 2011-2013.

181. H. Firouzabadi, N. Iranpoor, A. A. Jafari, and S. Makarem, J. Mol. Catal. A-Chem., 2006, 250, 237-242.

182. C. García-Sancho, R. Moreno-Tost, J. M. Mérida-Robles, J. Santamaría-González, A. Jiménez-López, and P. M. Torres, Catal. Today, 2011, 167, 84-90.

183. J. I. Garcia, H. Garcia-Marin, J. A. Mayoral, and P. Perez, Green Chem., 2010, 12, 426-434.

184. L. Aldea, J. M. Fraile, H. García-Marín, J. I. García, C. I. Herrerías, J. A. Mayoral, and I. Pérez, Green Chem., 2010, 12, 435-440.

185. M. Sutter, L. Pehlivan, R. Lafon, W. Dayoub, Y. Raoul, E. Métay, and M. Lemaire, Green Chem., 2013, 15, 3020-3026.

186. H. Garcia-Marin, J. C. van der Toorn, J. A. Mayoral, J. I. Garcia, and I. W. C. E. Arends, Green Chem., 2009, 11, 1605-1609.

100 187. H. Garcia-Marin, J. C. van der Toorn, J. A. Mayoral, J. I. Garcia, and I. W. C. E. Arends, J. Mol. Catal. A-Chem., 2011, 334, 83-88.

188. M. de Torres, I. W. C. E. Arends, J. A. Mayoral, E. Pires, and G. Jimenez-Oses, Appl. Catal. A-Gen., 2012, 425, 91-96.

189. L. Aldea, J. I. Garcia, and J. A. Mayoral, Dalton Trans., 2012, 41, $8285-8289$.

190. S. A. Herbert, D. C. Castell, J. Clayden, and G. E. Arnott, Org. Lett., 2013, 15, 3334-3337.

191. M. Pérez-Sánchez, Á. Cortés Cabrera, H. García-Martín, J. V. Sinisterra, J. I. García, and M. J. Hernáiz, Tetrahedron, 2011, 67, $7708-7712$.

192. J.-S. Chang, T.-R. Ling, T.-C. Chou, and L. C.-S. Chou, US Pat., 2013/133245 A1.

193. J. Kesling, L. J. Karas, and J. Liotta, 1 US Pat., 1994/5308365 A.

194. D. S. Bradin, US Pat., 1996/5578090 A.

115 195. T. M. Lovestead and T. J. Bruno, Energy Fuels, 2011, 25, 25182525.

196. J. U. Park, J. J. Choi, M. J. Gu, G. in Jeong, S. Y. Chang, S. E. Park, and B. J. Song, KR Pat., 2012/0035891 A.

197. F. J. Marinho and B. Yang, US Pat., 2009/266519 A1.

120 198. T. Wenger, CH Pat., 1989/670832 A5.

199. B. Wowk, M. Darwin, S. B. Harris, S. R. Russell, and C. M. Rasch, Cryobiology, 1999, 39, 215-227.

200. M. L. Maminski, R. Szymanski, P. Parzuchowski, A. Antczak, and K. Szymona, BioResources, 2012, 7, 1440-1451.

125 201. E. S. Vasiliadou and A. A. Lemonidou, Org. Process Res. Dev., 2011, 15, 925-931.

202. S. Xia, Z. Yuan, L. Wang, P. Chen, and Z. Hou, Bioresour. Technol., 2012, 104, 814-817.

203. M. G. Musolino, L. A. Scarpino, F. Mauriello, and R. Pietropaolo, ChemSusChem, 2011, 4, 1143-1150.

204. M. L. Barbelli, G. F. Santori, and N. N. Nichio, Bioresour. Technol., 2012, 111, 500-503.

205. T. Willke and K. Vorlop, Eur. J. Lipid Sci. Technol., 2008, 110, 831-840.

135206 . G. Kaur, A. K. Srivastava, and S. Chand, Biochem. Eng. J., 2012, 64, 106-118.

207. S. Casali, M. Gungormusler, L. Bertin, F. Fava, and N. Azbar, Biochem. Eng. J., 2012, 64, 84-90.

208. P. Anand and R. K. Saxena, New Biotechnol., 2012, 29, 199-205.

140 209. A. Malaviya, Y.-S. Jang, and S. Y. Lee, Appl. Microbiol. Biotechnol., 2012, 93, 1485-1494.

210. C. Moon, C. Hwan Lee, B.-I. Sang, and Y. Um, Bioresour. Technol., 2011, 102, 10561-10568.

211. P. G. Jessop, Green Chem., 2011, 13, 1391-1398.

145 212. C. Reichardt, in Solvents and Solvent Effects in Organic Chemistry, Wiley-VCH Verlag GmbH \& Co. KGaA, 2004. 
Instituto de Sintesis Quimica y Catálisis Homogén

213. P. G. Jessop, D. A. Jessop, D. Fu, and L. Phan, Green Chem., 2012, 14, 1245-1259.

214. J. I. García, H. García-Marín, J. A. Mayoral, and P. Pérez, Green Chem., 2013, 15, 2283-2293.

5 215. L. Moity, M. Durand, A. Benazzouz, C. Pierlot, V. Molinier, and J.-M. Aubry, Green Chem., 2012, 14, 1132-1145.

216. A. Benazzouz, L. Moity, C. Pierlot, M. Sergent, V. Molinier, and J.-M. Aubry, Ind. Eng. Chem. Res., 2013, doi 10.1021/ie402410w. 